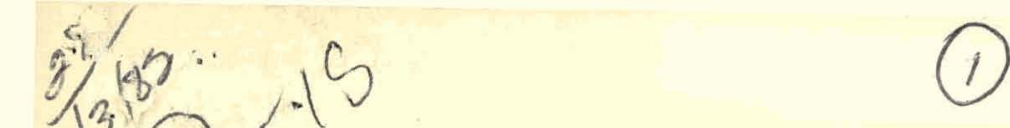

CONTRACTOR REPORT

$$
I-1725
$$

SAND81-7033

Unlimited Release

UC-63

\title{
High-Aspect-Ratio Silicon-Cell Metallization Technical Status Report
} Final Report

\section{NOTICE}

PORTIONS OF THIS REPORT ARE ILLEGIBLE. IT PORTIONS OF THIS REPOR ARE best available
has been reproduced from the possible avail
copy to permit the broadest possib ability.

Boeing Aerospace Company

Seattle, Washington 98124

Prepared by Sandia National Laboratories Albuquerque, New Mexico 87185 and Livermore, California 94550 for the United States Department of Energy under Contract DE-AC04-76DP00789

Printed January 1982 


\section{DISCLAIMER}

This report was prepared as an account of work sponsored by an agency of the United States Government. Neither the United States Government nor any agency Thereof, nor any of their employees, makes any warranty, express or implied, or assumes any legal liability or responsibility for the accuracy, completeness, or usefulness of any information, apparatus, product, or process disclosed, or represents that its use would not infringe privately owned rights. Reference herein to any specific commercial product, process, or service by trade name, trademark, manufacturer, or otherwise does not necessarily constitute or imply its endorsement, recommendation, or favoring by the United States Government or any agency thereof. The views and opinions of authors expressed herein do not necessarily state or reflect those of the United States Government or any agency thereof. 


\section{DISCLAIMER}

Portions of this document may be illegible in electronic image products. Images are produced from the best available original document. 
Issued by Sandia National Laboratories, operated for the United States Department of Energy by Sandia Corporation.

NOTICE: This report was prepared as an account of work sponsored by an agency of the United States Government. Neither the United States Government nor any agency thereof, nor any of their employees, nor any of their ment nor any agency thereof, nor any of their employees, nor any of their contractors, subcontractors, or their employees, makes any warranty, express
or implied, or assumes any legal liability or responsibility for the accuracy, or implied, or assumes any legal liability or responsibility for the accuracy, cess disclosed, or represents that its use would not infringe privately owned rights. Reference herein to any specific commercial product, process, or service by trade name, trademark, manufacturer, or otherwise, does not necessarily constitute or imply its endorsement, recommendation, or favoring by the United States Government, any agency thereof or any of their by the United States Government, any agency thereof or any of their contractors or subcontractors. The views and opinions expressed herein do not necessarily state or reflect those of the United States Government, any agency thereof or any of their contractors or subcontractors.

Printed in the United States of Americe Available from

National Technical Information Service

U.S. Department of Commerce

5285 Port Royal Road

Springfield, VA 22161

NTIS price codes

Printed copy: A02

Microfiche copy: A01 

1.0 Program Objective 1

Objective: High Aspect Ratio Metallization 1

Objective: Selective Texturization 2

2.0 Contract Tasks 2

Introduction $\quad 2$

Task 1.0 - High Aspect Ratio Silicon Cel1 Metallization 3

Photoresist Plating Mask 3

Silver Plating Bath Composition 4

DC - Plating Methods . 5

Pulse Plating Methods 6

Aspect Ratio and Line Edge Profile $\quad 6$

Line Conductivity Evaluation 8

Task 2.0 - Selectively Textured Silicon Cell Etching 12

Fine Line Resolution 12

Contact Resistance of Electrode to Silicon 13

Junction Leakage on Textured Cells 15

Texture Etch Process Control 16

Task 3.0 Production of Sample Cells 1.9

3.0 Summary - Results and Conclusions 20

\section{ILLUSTRATIONS}

\section{FIGURE}

Dual Cell Design With Test Patterns

Collector Electrode on Face of Selectively Textured Concentrator Cell SEM Photo of A Cruss-Bectional View of A Rcoict Crove Resist Profile Characterization Pulse-Plating Test Matrix SEM Photo of A DC Plated Line With Resist Mask $\left(2,000 \mathrm{x}: 45^{\circ}\right)$

SEM Photo of A Pulse-Plated Line With Resist Mask $\left(2,000 \mathrm{X}: 45^{\circ}\right)$

SEM Photo of A Pulse-Plated Line With Resist Removed $(2,000 \mathrm{X})$ Conduction Efficiency Parameter, Cs, for Various Plating Conditions Apparatus for Pulse-Plating Current and Voltage Monitor SEM Photos of Photo-Resist Lines on A Textured Surface Contact Resistance as A Function of N-Layer Resistivity Correlation Between $\mathrm{N}$-Layer Resistivity $\mathrm{r}_{\mathbf{s}}$ and Test Pattern Readings Rs Textured Surface. Showing Carbon Contamination Effect of Texture Etch on Wafer With No Prior Processing Effect of Texturc Etch on Wafer With Mask Processing Only Effect of Texture Etch on Wafer With Both Diffusion and Mask Processing Selective Texlurizing Etch Test Summary Selcctive Etched Diffused Wafer, ( $1: 1$ Hydrazine at Room Temperature) 
Selective Etched Diffused Wafer ( $1: 1$ Hydrazine at Room Temperature)' Schematic Representation of A Concentrator Solar-Cell Test Facility Efficiency Versus Concentration for A Boeing Rectangular Dual Cell With Dimensions of 1.0 by 1.6 Inches

\section{TABLES}

\section{TABLE}

Selective Texturization Etch of Diffused Wafers in 1:1. Hydrazine at Room Temperature

Selective Texturization Etch Using A Two-Step Process in 1:1 Hydrazine 


\subsection{PROGRAM OBJECTIVE}

The objective of this program was the improvement of single crystal silicon concentrator cell performance by improving the aspect ratio of the solar cell metallization and by developing a process for selectively texturizing the front surface areas of the cell not covered by electrodes. The ultimate aim was to extend the peak efficiency of large area concentrator cells to higher concentration levels and to maintain peak efficiency over a broad range of concentration -70 to 150 suns or more.

Because the current becomes very large at high concentration, anything which impedes current collection is seen as contributing to the efficiency fall-off. Therefore, a series resistance tolerable at low concentration levels becomes intolerable at high levels. Sources contributing to series resistance are collector line resistance (which is a function of line cross-sectional area and volume resistivity of the specific electrode metal as deposited), contact resistance of the electrode to silicon interface, and the sheet resistance of the diffused region. Improvement to all three of these principal sources of series resistance was addressed by this project, but the project had two main thrusts, namely, 1) improved metallization conductivity and aspect ratio and 2) selective texturization for preservation of low contact resistance, aspect ratio and minimum risk from junction shorts, and a smooth surface for a high resolution metal grid.

\section{Objective: High Aspect Ratio Metallization}

The first major thrust of the project was the improvement of the metallization grid design and the development of the processing methods necessary to achieve that design. This design consists of an increased metal cross-sectional area, without increase in shadowing, achieved by electroplating lines which have a high height to width ratio. The approach used was to develop a plating mask and plating process which would result in such characteristics. However, a major part of the collector iine resistance problem lies with the plated conductor material itself. Characteristically, electroplated coatings have a higher resistivity than the resistivity of the bulk material. This is caused in part by porosity and by grain refining additives or other impurities added to the plating bath to simplify bath control and improve deposit appearance. These impurities alloy or codeposit with the plated metal and affect its conductivity out of proportion to their concentration. An increase in resistivity of $2 \mathrm{X}$ or more over the bulk pure metal values is not uncommon. Therefore, improvement in conductivity is fully as important as high aspect ratio. The approach used here was to control bath formulation by avoiding proprietary commercial plating baths and using pure metal formulations only, and to maximize deposit density by advanced techuiques such as pulsc plating and perionir reverse plating. 


\section{Objective: Selective Texturization}

The second major thrust of the project was the developmenl of a selective texturization process which results in flat mesas for the electrode lines. The top surface of these mesas retains the original polished wafer surface. Thus, the problems normally associated with producing high resolution fine lines on a textured surface would be eliminated by this process and the plated line edge definition more easily preserved.

Selective texturization provides some further opportunities for optimized device performance, in addition to the benefits ascribed to improved light absorption of the textured surface. Normally, solar cell design calls for a rather shallow diffused region, but the shallow junction mitigates against optimum contact resistance between electrode and silicon and increases the risk of the metal punching through and shorting the junction. Selective texturization allows us to separate these conflicting requirements and produce a deep junction under the electrode and a more appropriate shallow diffuslon in the open area. This is accomplished by first diffusing a deep junction over the entire wafer surface followed by the usual oxidation step at llie conclusion of the diffusion cycle. The oxide is etched to serve as a mask which will preserve the grid line mesas. The anisotropic silicon etch is used to generate. the texture everywhere except where the oxide protects the surface. This texture etch at the same time removes the first diffused junction which is approximately a micron deep. The wafer is then given a second shallow diffusion. The rcsult is a deep junction on the grid line mesas, while the open textured area has only a shallow junction. By proper sequence of operations, no additional process steps are necessary to effect this additional control other than the second diffusion itself.

\subsection{CONTRACT TASKS}

\section{Introduction}

The program has been divided into three tasks: 1) high aspect ralio metallization design, 2) selective texturization, and 3) production of sample cells. All three tasks have been designed to use the same test vehicle which consists of two large area $n$ on $p$ concentrator cells of rectangular design constructed on a 2 inch diameter silicon wafer.

The test vehicle starting material was a float zone wafer, boron doped to .l to $.2 \mathrm{ohm}-\mathrm{cm}$ resistivity. Wafers were procured from Wacker-Siltronic with front side polished and back side chemically etched. Orientation was (100) to permit texture etching. Some wafers were procured as ingots and sliced and polished by Seinicondurtnr Proressing to evaluate variables resulting from surface finishing.

A rectangular design was employed, as shown in Figure 1, with approximate dimensions of $1 \times 1.6$ inches. The grid pattern employs a main collector bus on each side of the pattern's long dimension. The fine line grid utilizes a 10 mil center to center spacing with a 5 mil gap at the center between the two cells. This gap permits division of the unit into 2 separate cells, each with a single bus, so that shingled arrays can be fabricated. The finished cells, therefore, measure approximately $.5 \times 1.6$ inches. Test patterns and alignment marks were included around the wafer periphery to facilitate line conductivity and contact resistance measurements, and mask registration. 
A brief description of the remaining wafer processing is beneficial at this point to understand how the project tasks are incorporated into the overall process sequence:

After the second diffusion, a combination drive-in/passivation oxide step is performed. The latter also serves as an antireflective coating. Windows are etched in this oxide for the metal grid lines and main buses. The PR used in this window etch remains on the wafer while conventional TiPdAg metal is evaporated. The grid lines are delineated by a lift off technique. The task 1 plating mask and electroplating processes are performed and after cleaning and separation, the cell processing is complete.

The mask set for the cell is constructed so that there is a slight reduction in line width with succeeding layers to simplify registration and avoid any problems with metal contacting the shallow junction region because of slight misalignment. This is best illustrated by the idealized cross-sectional drawing of a grid line, shown in Figure 2. The generous tolerance allowance for nesting of the layers was arbitrarily selected to obviate need for extreme care in alignment. Reduced tolerance limits will be established after experience with the process.

\section{Task 1.0 High Aspect Ratio Silicon Cell Metallization}

Build up of the evaporated metal electrodes by electroplating without a plating mask invariably results in sidewise growth of line width. Each side of the line grows sidewise an amount equal to the height growth resulting in a widening of about $2 X$ the height build up. Plating beyond 4 to $5 \mathrm{~A} / \mathrm{m}$, therefore, becomes nonproductive because of the increase in shadowing which occurs. With a plating mask, the line can be confined to a narrow channel and the growth directed upward.

\section{Photo Resist Plating Mask}

Selection of a suitable plating mask material is an important decision with few options because not many materials are available with the required characteristics of high resolution and suitable thickness. We have used an experimental dry film resist made available to us by the Shipley Company. The film, designated XP-17000 was produced in .5 mil and .7 mil thicknesses. The film is positive working, has adequate resolution to resolve $.5 \mathrm{mil}$ lines and has sufficient chemical resistance to the silver cyanide plating solution for the short periods required, although prolonged exposure (hours) will affect adherence.

A plating mask of this thickness, having line openings developed with vertical side profiles should theoretically allow lines .7 mil high to be plated without any lateral line spreading. However, implementation of this ideal is contingent on a sharp vertical line edge profile which is not obtained in practice. An actual mask opening profile is shown in Figure 3, which is a Scanning Electron Micrograph (SEM) picture of a wafer edge broken at right angles to a line groove. Comparisons of measurements taken from such SEM photographs and observations with a metallographic microscope and light section microscope have led to the interpretation shown in Figure 4 which shows a typical dry film resist line groove in cross-section. Typical dimensions of the groove profile are shown at 
the top of the figure. The corresponding images as they appear in a light section microscope and a metallographic microscope are shown below. The interpretation of the image seen in the optical microscopes as the focus is changed is important since these are the primary inspection tools used to evaluate the PR mask after development. The SEM photographs require destruction of the sample and therefore cannot be used for in-process evaluation.

Processing of the dry film deviated slightly from the manufacturers recommendations. The modifications below produced better results than the recommended procedures. The deviations were minor e.g. lamination was performed in a shoe type laminator rather than a roller heated type and parts were not preheated. The processing flow is detailed below:

1) Dehydration bake: $250^{\circ} \mathrm{F}$. for 30 minutes.

2) Cool parts to room temperature.

3) Laminate (d $2650 \mathrm{~F} .+50 \mathrm{~F}$. Ior both top and bottom shoes.

4) Speed setting 1.5 inches/minute.

5) Remove cover sheet and backing.

6) Prebake $1850 \mathrm{~F}$. for 20 minutes.

7) Expose $15 \mathrm{sec}$. (varies with equipment).

\$) Develop 2 minutes in XP-77 17-7 developer.

9) No post-bake.

Post-baking of the dry film is not recommended as the line edge profile is adversely affected.

Because resist layers of even greater thickness would be desirable, experiments were run on double laminations of .5 mil dry film for a total thickness of 1.0 mil. The lamination itself could be performed by striping the backing sheet from the first lamination and then immediately laminating the second layer without a prebake. This was the most successful procedure and produced well adhered, bubble free laminations. Exposure and development of these fllms, however, did not prove to be possible. Apparently the release agent used under the dry film backing retards development and the film is severely undercut. Line widths on the order of 2.0 mils wide were the best obtainable, which represents considerable overdevelopment from the .5 mil master. Plating mask thicknesses were therefore limited to .7 mil, the maximum thickness of dry film availablc as a single layer film.

\section{Silver Plating Bath Composition}

Silver plating through these plating masks was performed in pure metal cyanide plating baths. Preliminary plating tests were conducted on various bath formulations in order to select compositions ranges which yield maximum conductivity with acreptable mechanical properties. These tests were all performed using dc plating at low current density and the conductivity tests were comparitive, i.e., a known line length was measured after plating to a measured thickness, but an accurate determination of the line cross-sectional area was not made. The importance of the latter feature on fine line geometries for absolute conductivity measurement will be discussed later in this report.

Two bath formulations were selected for continuing tests to establish any preference between high and low concentration baths. The first bath is representative of a conventional bath used for decorative purposes, although the 
silver concentration is at the high end of the range normally employed for this purpose. The second bath is a high speed formulation with approximately $1.5 \mathrm{X}$ greater silver concentration and correspondingly lower free cyanide and carbonate content. The latter changes were designed to reduce throwing power and thus to suppress excessive plating on line edges. Neither bath contained any organic or inorganic additives, brightener or wetting agents. Reagent grade chemicals were used for the two formulations which are shown below, except the AgCN which was an electroplating grade.

Bath 1

Low Silver

$\mathrm{AgCN}$

$\mathrm{KCN}$

$\mathrm{K}_{2} \mathrm{CO}_{3}$

Temp. ${ }^{\circ} \mathrm{C}$.
$48 \mathrm{~g} / 1$

65

40

20-21
Bath 2

High Silver

$75 \mathrm{~g} / 1$

15

$38-40$

As testing of these two formulations continued no particular advantage appeared to ascribe to Bath 2. This is because most of the dc plating was performed at low current density $\left(1 \mathrm{amp} / \mathrm{dm}^{2}\right)$ where the higher speed characteristics of this bath were of no advantage. Bath 1 with its room temperature operation was easier to maintain and operate and was therefore used for all further testing.

\section{Dc-Plating Methods}

Pure silver anodes were used with an anode-cathode separation of about 5". Masking lacquer was used to shield contact clips, but the back of the cell was contacted and allowed to plate by current throwing around to the back. The only metal exposed to the bath was evaporated silver, therefore it was not necessary to use a strike bath. Silver is soluble in this cyanide containing bath (anode efficiency is greater than 100\%) therefore the cells were introduced to the bath without applied power and the evaporated metal allowed to dissolve for a few moments as a self cleaning action. The anodes were removed from the bath after each plating period for the same reason, i.e., to prevent undue dissolution of silver in the bath which would throw off the free metal content. A current regulated dc supply was used and the current level gradually increased over the first 5 minutes to the preset value. This helps to eliminate voltage drops in the thin evaporated coating by allowing the thickness to build up gradually.

Dc plating through the dry film mask produces very fine grained, smooth, but dull coatings. The thickness uniformity is excellent across the substrate. Adhesion was adequate for the $.7 \mathrm{mil}$ thickness, but heavier coatings $(2$ mil thick coatings which have mushroomed over the top of the mask) showed a tendency to peel up at line ends. (This is a very severe condition since the mushroomed coating has a large cross-section, but only a small area of attachment to the substrate.) While stress measurements were not made, this kind of behavior is indicative of tensile stress in the coating which exceeds the adhesion to the substrate. (The limiting adhesion is at the evaporated metal to silicon interface.) Evidently there is a slight amount of residual tensile stress in these $d c$ plated coatings in spite of the precautions taken with bath purity. However, as noted, no adhesion problem was experienced with normal coating thickness. 


\section{Pulse Plating Methods}

Pulse plating methods were also investigated. Because pure metal baths without additives are more difficult to control than commercial baths owing to their sensitivity to minor changes, one would expect that desirable features such as good conductivity and density also would be sensitive. We therefore sought to compensate by exploring advanced plating techniques which have proved helpful with other types of metal plating solutions. Pulse plating is one of these techniques. Pulse plating is a method of plating in which short pulses of dc or asymmetrical ac current are applied with variable delay or off periods. For this aspect of the investigation a Dynatronic DP20-10-30 power supply was used. This supply generates an essentially square shaped $d c$ pulse which can be varied from $.1 \mathrm{amp}$ to $20 \mathrm{amp}$ peak height with a pulse width from .1 to $10 \mathrm{~ms}$. The delay or off time between pulses is variable from .1 to $100 \mathrm{~ms}$. Because the average current density is a function of not only peak amperage, but also of the ratio of pulse width to off time, the analysis of plating results becomes quite. complicated with many possible combinations of plating conditions. To resolve this problem a pulse plating test matrix was processed to systematically block out the fields which yield useful coating characteristics. Visual characteristics, such as uniformity and grain size were evaluated at two different average current densities. All tests were made in Bath 1 . The test matrix is shown graphically in Figure 5. The test results indicate that the higher average current density normally produces nonuniformity and coarse grain except in the lower left hand corner where a uniform thickness distribution is combined with a fine grained deposit. Uniformity of thickness is of course a necessary desirable feature for solar cell electroplating, but coarseness of grain would not eliminate a deposit from consideration for this application.

Small quarter cell test samples were used in the matrix test which somewhat limits the possible combinations of conditions. Longer pulse lengths at large on/off ratios were not possible with these small samples at these average current densities because the peak currents then become too small to be controllable. This explains why the upper part of the matrix field contains no test samples.

Pulse periodic reverse plating was also employed. In this technique both forward and reverse current pulses are used with the reverse pulse taking place during what would have been the off time in normal pulse plating. This technique requires two pulse plating supplies connected oppositely in a master/slave arrangement which uses only the timing generator of the master unit. This initiates the reverse pulse when the forward pulse goes off. No off time is employed in this technique so the average current densities can become very high even though their algebraic sum is normal. An alternative method was also used which allows the forward and reverse supplies to run randomly without synchronization. In this case the off time is retained on each supply. Pulse plating and deplating proceed independently and at times the pulses cancel each other. With both methods the number of possible combinations of plating conditions becomes very large and their analysis extremely complicated.

\section{Aspect Ratio and Line Edge Profile}

The dc plated line edge profile, as it builds up in the mask opening, seems to faithfully follow the resist side wall contour and the line completely fills the mask opening. This unfortunately results in the line profile being severely 
tapered as shown in Figure $6^{*}$. Dc plating to the full .7 mil thickness results in line broadening to about 1.0 mils. In contrast the pulse plated lines.. appeared to have much straighter side walls and appeared capable of greater thickness without mushrooming. These observations have been verified by plating on resist masks of very sirnilar profile, each individually characterized optically as conforming to the profile indicated in Figure 4. The SEM photograph in Figure 6 shows a dc plated line with the resist still intact. The line is plated to the height of the sharp step and has not yet begun to mushroom. The close conformity to the resist wall is clearly evident. Similar SEM photos of a pulse plated line are shown in Figure 7. The gap between the resist wall and the plated line extends to the silicon surface. In fact, the silicon surface can be visually observed in places when the sample is properly oriented. The plated line width is several tenths of a mil narrower than the resist opening at the step. Figure 8 shows a pulse plated line with resist removed indicating steep side walls. Pulse plated lines seem capable of extending slightly above the step level without broadening, but eventually do mushroom as plating continues. Consequently, the resist mask is still necessary even though pulse plating is used. The combination of resist mask and pulse plating results in narrower and taller lines with better edge definition.

The physical explanation of the above result is highly speculative at this point. One possible explanation might be as follows:

In the $\mathrm{dc}$ case the cathode film formation is the governing factor and regulates plating rate. The entire line lies in a recess (the resist mask), but the significant feature is the cathode film which is thick enough to fill the whole channel width even though the etched metal line at the bottom may not extend across the entire width. The transfer rate of $\mathrm{Ag}$ ions from solution to metallic $\mathrm{Ag}$ on the line is governed by the concentration of ions in the film and so proceeds uniformly in all directions. The line quickly broadens to fill the resist channel and continues to plate sinoothly, filling the channel and following the wall contour. Another way of stating this is that the presence of the thick cathode film moderates any local differential ionic diffusion effects which otherwise might occur.

The pulse plated case is different. Most of the plating takes place at the initiation of the pulse before the cathode film can form. Local ionic diffusion now takes place on a micro scale at the metal surface. During the off time, concentration equilibrium is re-established so the cathode film never gets thick enough to affect adjacent areas.

Plating rate is now governed more by local metal topography and the ease of direct access of the ions diffusing from the bulk of the electrolyte. The latter favors build-up in the center of the channel where ions have easiest access so

* Plating conditions may create exceptions to this, e.g. agitation could upset the cathode film at the line center more than at the line edge (see discussion following). Other workers have reported instances where dc plated lines did not follow the mask contour. We have not observed this with our plating conditions and mask material. 
the line becomes rounded on top. This creates deeper recesses at the side walls of the channel and the mechanism is self accentuating. As the line builds up. in height the edge gaps become deeper and ionic replenishment in this region becomes negligible with resultant cessation of sidewise build-up. Once the top of the channel is reached the edges have improved access to ions diffusing from the bulk solution and rapid sidewise build-up takes place. If plating is stopped at this point the rounding of the line center actually extends above the resist channel height.

Thus, although this is a fairly simplistic and highly speculative mechanism, it explains most of the observed effects.

One of the probable reasons why pulse plating is effective with silver cyanide solution' is that metallic silver is quite soluble in the bath. This results in a slight deplating of the cathode silver during the off cycle which helps to disperse the cathode film.

Pulse reverse plating has an even more pronounced effect on line profile. In this rase pulse plating and pulse deplating are taking place simultaneously each with a different program which can be separately controlled to preferentially favor high or low current density areas. A considerable gap between mask and plated line is possible and line contour can be-varied, e.g., the line edges may be built up and the center deprossed like a trough. Unfortunately, these effects are quite localized with considerable nonuniformity in thickness and line contour over the substrate area. Compromise programs which somewhat balance uniformity and line profile are difficult to devise due to the great number of possible variables. Minor bath conditions can cause major changes in the effects produced, e.g., at one point a good compromise program was established for the master/slave configuration on quarter cell plating samples. But this same program produced a very nonuniform result on full cells when adjusted for the same current density. Fine tuning of the plate/deplate cycle was further frustrated by the incremental (digital) controls of the power supply. Bracketing of the desired conditions was sometimes not possible becausc of poor resolution owing to the lack of intermediate settings. For these reasons, the pulse reverse technique was not tully exploited. Thie method appcars to have considcrable potential if systematic control methods could be devised and suitable plating conditions developed. Nonuniformity in samples plated by this method obviated its use on actual cells.

\section{Line Conductivity Evaluation}

Plated line conductivity was also measured. The grid line sheet resistance is a function of the plating conditions. Metal purity is of course a major factor. Any minor alloying with impurities rapidly decreases the conductivlty of llit deposited metal. Given the maximum allailable metal purity which we havr endeavored to achieve in our bath formulations, the conditions during plating are the principal variables affecting line sheet resistance. This is the result of intergranular resistance, porosity from gas inclusions, and the impurity concentration in the immediate vicinity of the cathode surface.

The conductivity measurement is not as simple as might be at first supposed. If an absolute value of conductivity is required (as contrasted to mere comparitive values), the line dimensions must be measured with accuracy. This is difficult with regard to the cross-sectional area of a narrow line because of the 
irregularity of the line edge profile.

Resistance of a plated line can be expressed as

$$
R=C \frac{L}{A}
$$

where $r$ is the volume resistivity and $L$ and $A$ are the line length and crosssectional areas respectively. While $R$ is a measured quantity, what we are really seeking to evaluate is the fundamental quantity, which will have its theoretical value when ideally pure and at maximum density; i.e., free of porosity and imperfections. The area $A$ is very difficult to measure accurately on narrow lines. Measurement would be simplified if we could use a weight basis for the amount of silver deposited rather than volume.

Since weight equals the density times volume:

$$
\begin{aligned}
& W=d V=d L A \\
& R W=: \frac{L}{A} d L A=\therefore d^{2}
\end{aligned}
$$

Note that the cross-sectional area A drops out of the equation in favor of the accurately measurable factor W.

The quantity $d$ then becomes a convenient figure of merit for conduction efficiency.

$$
\begin{aligned}
\mathrm{RW} / \mathrm{L}^{2}= & \mathrm{d} \\
& \mathrm{C}_{\mathrm{s}}=\mathrm{r}_{\mathrm{s}} \mathrm{W}_{\mathrm{s}} / \mathrm{d} \\
& \mathrm{C}_{\mathrm{s}}=\text { conduction efficiency parameter. }
\end{aligned}
$$

The conduction efficiency parameter $C_{5}$ combines preformance and weight into one descriptive number that serves as a material comparison guide for various plating conditions. The sheet resistance $r_{s}$ expresses the conductor performance and $W_{S}$ is the deposited weight required to obtain $r_{s}$. With $r_{s}$ in milliohms/square and $W_{S}$ in milligrams/inch 2 , the conduction efficiency factor $C_{s}$ has the units:

$$
\frac{\text { milli-ohms }}{\text { square }} \cdot \frac{\text { milli-grams }}{\text { square inch }}=\frac{\text { milligrams } / 1000 \text { mhos }}{\text { square inch }}
$$

Using these units, $C_{s}$ gives the number of milligrams required to cover one square inch with electrodes having a conductivity of 1000 mhos/square or a resistivity of 1 milliohm/square. High $C_{5}$ values indicate that large material quantities are required to achieve a 1000 mho conductivity. Small values identify a good conductor.

This weight method of assessing conductor efficiency is fairly simple to implement and has proved to be quite sensitive to various plating conditions.

In practice, the four point test pattern on the periphery of the wafer, as shown in Figure 1 was used in the conductivity measurement. The patterns were scribed and broken from the wafer edge and the weight of the entire chip obtained (before 
and after plating) on an analytical balance with .01 milligram resolution. Because the diffused layer also serves to conduct as a parallel resistance, we can expect some slight variation depending on the sample $n$-layer sheet resistance. Therefore, to eliminate any ambiguity, the $C_{s}$ parameter was measured and plotted as a function of the n-layer sheet resistance. The resultant plot is shown in Figure 9.

The horizontal line across the graph of Figure 9 represents the theoretical value of $\mathrm{C}_{\mathrm{s}}$ for pure bulk silver. As shown on the figure, the dc plated lines have an average $C_{s}$ value approximately $1.75 \mathrm{X}$ greater than the theoretical bulk value.

Pulse plated lines do not necessarily have better conductivity. Under condition $\mathrm{I}, .8 \mathrm{~ms}$ pulse length, $80 \mathrm{~ms}$ off time, the scatter of points is somewhat worse than the $\mathrm{dc}$ case and the average $\mathrm{C}_{\mathrm{s}}$ value is about the same. This is a short pulse length, which is the condition where one might expect the best conductivity to be obtained. An even shorter pulse length, such as condition II, .2 ms and an $80 \mathrm{~ms}$ off time, produces a surprising degree of change and $\mathrm{C}_{\mathrm{s}}$ values equivalent to bulk values are obtained. The extreme off time of $80 \mathrm{~ms}$ is not an actual requirement to obtain improved conductivity, but the off time must be sufficient to allow complete re-establishment of equilibrium conditions.

One factor in this effect is that both the silver. ions and the impurity ions are present in the bath and will plate out at the cathode, but not at the same rate. The impurities plate out less efficiently. Initially, when the pulse comes on there is a high concentration of silver in the bath near the cathode. As plating continues, silver is depleted in the film near the cathode surface. Therefore the concentration of impurities in the film goes up. The next increment of plated metal will therefore have a higher impurity concentration. If plating is terminated by a very short pulse, this next increment is not deposited and concentration equilibrium is re-established during the off time. Another factor is the physical nature of the deposit. The shorter pulse deposit is coarser grained, which provides for less intergranular resistance.

The improvement in conductivity is 1.5 to $2.0 \mathrm{X}$ better than the $\mathrm{dc}$ plated case. This fact alone would be sufficient to justify the use of pulse plating for silver electrode buildup on concentrator cells. The improvement is not automatic, but requires that the proper short pulse length conditions be established and controlled. These extremely short pulse lengths place some restrictions on the power supply characteristics which may not be immediately obvious. Power supply features are discussed below.

Questions regarding the power supply characteristics arose early in the investigation when a number of inconsistencies were noted between calculated plating time and that observed in practice. Accuracy of the current level during the pulse was suspect and information on the rise time was not available. Pulse plating literature contains references to a nonfaradaic component of the plating current which does not contribute to metal deposition. This nonfaradaic current is that current required for the formation of the double layer cathodic film and is reported to be largest when the pulse first turns on and gradually diminishes as the charged layer forms. Thereafter the current is entirely faradaic. In view of the short pulse and unknown faradaic effects, it was important to characterize these particular plating conditions and if possible establish approximate values for lumped parameters in the bath equivalent circuit. Understanding the electrochemical mechanism would reveal 
reasons for the anomalies observed and point the direction for process improvement. Accordingly, a dual channel scope (TEK 465) was connected to monitor both voltage across the supply and current measured through a 20 ampere shunt at the cathode. The test circuit hook-up is shown in Figure 10, in block diagram form.

Voltage and current were monitored and pulse waveform evaluated for a number of different pulse plating conditions, including the empirically determined "best" programs. The supply output was monitored during actual plating with the standard No. 1 bath, using a five inch anode/cathode stand off distance, and also with selected resistor and resistor/capacitor networks connected in place of the bath. Half cells were used in the bath tests with power supply settings for the optimized program as follows:
$\mathrm{i}_{\mathrm{p}}=11.2 \mathrm{amp}$
$\mathrm{T}$ on $=.1 \mathrm{~ms}$
$\mathrm{T}^{\prime}$ off $=80 \mathrm{~ms}$

One of the first things discovered was current limiting at slightly over six amperes regardless of the pulse length or off time settings, even though the supply is capable of 30 amperes output. Up to this point we had no data on the bath resistance, but had assumed it to be low. A quick check of the voltage trace revealed that this assumption was incorrect. In the current regulating mode the supply was trying to raise the current to the called for level of 11.2 amp by increasing the voltage. At 28 volts the current had only reached $6.2 \mathrm{amp}$. The bath resistance was actually 4.5 ohms. $R=E / I=28 / 6.2=4.5$ ohms. Meters on the supply show the average current and voltage (the dc equivalent) so that at the low duty cycle used the meters show virtually no indication at all. Thus, there is no way of knowing that the power supply limits have been reached without a scope monitor on peak values. No panel indicator on the supply warns of this condition. Substitution of resistors in place of the bath verified that the supply was functioning normally and the $4.5 \mathrm{ohm}$ bath resistance was correct.

The pulse waveform is essentially a square wave for both voltage and current. At the .l ms pulse length a $30 \mathrm{~s}$ rise and fall ramp was measured. The wave shape is almost identical for both the bath and substituted resistors. The wave shape is not affected by current regulation mode vs. voltage regulation mode as long as the output voltage is adjusted to the same level. The wave shape does deviate with a rounding of the leading edge as the voltage limit of the supply is approached. Polarization of the hath electrodes is indicated by a fixed $d c$ voltage bias above ground level which persists like a remnant polarization through the entire off time. As pulse length is increased this off-set level $\mathrm{dc}$ voltage increases, but shows no significant decay during the course of the off period. Significantly, this polarization bias voltage is not present at the short pulse lengths in our programs nor at any pulse length less than $.5 \mathrm{~ms}$ with long off times. Even with short pulse length, there is a slight deviation in the trace indicating that polarization is just beginning when the off times are reduced experimentally to values close to the pulse length. At the $80 \mathrm{~ms}$ off times used, however, there is no trace of polarization and probably this long off time could be reduced considerably without introducing any polarization effect.

The conclusion is that the bath behaves essentially like an ohmic resistor circuit with a dc bias on the higher duty cyle programs, but without any bias at the programs being used. The nonfaradaic current is not seen as a discernible voltage/current differential in the programs being used. 


\section{Task 20 Selectively Textured Silicon Cell Etching}

As indicated in the introductory section, a number of objectives are served by selective texturization in addition to the obvious increase in light absorption. The roughness of a textured surface produces two practical problems which selective texturization eliminates. These are the resolution of narrow grid lines and the difficulty of optical alignments on a surface which scatters light. Secondly, the deep diffusion on the electrode mesas ensures against junction shorts under the electrode and provides for a low contact resistance regardless of how shallow the junction in the open area may be. The optimization of this double diffusion process is a subject of this study. We have also investigated cell leakage which is an occasional yield problem on textured cells. And finally we have developed the texturization etch process itself for optimum consistency and best cell properties.

\section{Fine Line Resolution}

One of the principal advantages of the selective texturization process is the flexibility provided for processing the fine line geometries. Line dimenslons are not in any way limited by the surface condition. The line area retains the original polished surface. Textured surfaces can exhibit peak heights and base dimensions of typically $5-10 \mathrm{~m}$, which approaches the line width dimensions commonly used for concentrator cells. Photo resist line delineation on such a surface is subject to poor edge definition, is more critical in exposure and development, and results in poor yield because of breakdown in thin areas where the peak tops protrude.

The problems are illustrated in Figure 11 where a SEM photo of a resist line on a textured surface is shown. The critical nature of photo resist processing on such a surface is shown by the fact that the line edge is already starting to degrade where peaks are crossed, yet there are still unclear ridges of partially developed resist in open areas near the line edge. Any further development would cause peaks to protrude through the line and line edges to become more ragged. The selective texturized surface with its polished mesas is free of these resist processing problems.

Another problem is image definition and visibilit" while making an alignment of a mask over an existing pattern. Alignment is a commonly required step in many concentrator cell processing sequences. This problem is less easy to demonstrate because of the difficulty of photographing the alignment image. The scattering of light from the textured surface makes small step heights, such as oxide windows, almost impossible to see in the aligner microscope. About the only way such an alignment can be done accurately is to use alignment marks outside the active ccll arca on the wafer periphery using a special area protected from the texture etch. Selective texturizing is simply an extension of this same idea to the entire electrode area and completely eliminates any alignment problems.

To further facilitate ease of alignment on this program, we have used transparent iron oxide masks where negative masks are required. These masks are transparent to the red end of the visible spectrum, but opaque to the ultra-violet light to which the photo resists are sensitive. This completely eliminates dependence on alignment marks. 


\section{Contact Resistance of Electrode to Silicon}

An important element of the total series resistance of a solar cell is the contact resistance between the silicon and the metal electrode. For this contact, an ohmic contact is commonly discussed as if the "ohmic" characteristic was sufficient. Actually what is needed is not only an ohmic characteristic, but also a low contact resistance. Our interest has therefore been directed toward the independent measurement of the contact resistance. The vehicle used for this measurement is a four point test pattern consisting of concentric loops as shown in Figure 1. The large area of the loops in contact with the silicon was felt to be desirable because slight differences in resolution or etching would present less percentage error than a point pattern. This type pattern introduces no error where the contact resistance is fairly high and the metal resistance is very low, i.e., the metal is thick enough so that no voltage drop occurs as a result of metal resistance. Such is the case with thick film contacts for which this pattern was initially designed.

The application of this type pattern to the present thin film case has been looked at critically and the interpretation of the derived measurements evaluated. We had earlier observed that during cell electroplating the contact patterns around the periphery of the wafer acquired an electroplated coating even though they are isolated and connected to the plating power supply only through the silicon. This observation was made on samples with a low $n$-layer sheet resistance. The final plating thickness on the patterns was somewhat thinner than on the connected cell pattern. Comprehensive plating thickness measurements on these contact patterns indicates that the plated thickness shows a strong dependence on $n$-layer sheet resistance. Less plating takes place on the isolated patterns on samples with high sheet resistance. This result shows that the n-layer acts as a series resistor during plating and limits the voltage appearing at the contact pattern. What was unexpected was the magnitude of the effect and the fact that even the cell grid pattern which was connected directly to the power supply shows a similar variation with $n$-layer sheet resistance. The n-layer in the case of the cell grid acts as a parallel resistor and thus affects uniformity along the line length.

These findings have an incidental effect on the interpretation of contact resistance measurements made from these patterns. The requirement for a sufficiently low resistance from one side of a contact pattern loop to the other is not met for the thinly plated case. A finite series line resistance exists. When the metal is very thin the current path is concentrated around the probe, and proceeds through the silicon to the other probe. The area of the contact resistance is very small, i.e., the test is essentially done with a point pattern. As the metal thickness builds up, the current path spreads farther down the conductor. Thus the area over which the contact resistance is measured increases. Finally, when the metal is plated thick enough so that there is essentially no line resistance, the full area of the pattern is utilized. The " $r$ " readings obtained thus represent a combination of line resistance and contact resistance integrated over a variable area. The trade off in current paths is analogous to what the internally generated current sees in trying to get out of the cell.

A true measure of contact resistance could be obtained by the usual point type pattern, but the small contact areas would then be a difficult to contrul variable, e.g., when probe points are used the probe pressure must be carefully controlled to regulate the contact area of the points. Thus, the loop pattern is 
still desirable and serves another important function. This function is the demonstration of the line thicknesses that are necessary for an accurate contact resistance measurement without allowing line resistance to be a limiting factor. Bccause the total line length in the loop is about comparable to the finger length in the cell grid pattern, a measure of " $r c$ " gives information on the division of current flow in the cell. If " $r c^{\prime}$ is measured periodically during plating a point is reached where little further change is observed. At this point a very low voltage drop is occurring in the line and " $r$ " approximates closely the true contact resistance. Thus it should be possible to establish a point at which continued plating would have little further effect on " $r$ ". This point would represent the optimum plating thickness (assuming no ${ }^{C}$ sidewise growth).

This type of measurement simply involves heavy electroplating of the contact pattern without regard for the extreme mushrooming over the resist. The only concern is the reduction of line resistance to a negligible level. Note that the actual contact area is still accurately defined by itie resist and the original evaporated metal pattern at the silicon surface. For this experiment the lines were plated to a resistance of .1 that of a normal line (i.e., a line plated to the resist height). Figure 12 shows the contact resistance readings vs. sheet resistance readings taken on normal lines (triangles) and the heavy plated lines as indicated on the figure. The abscissa shows both pattern readings and the sheet resistance readings taken from Figure 13 which correlates four point probe readings with pattern readings.

As shown on the righthand portion of the curves there is very steep dependence of contact resistance at high $n$-layer sheet resistivity. As sheet resistance is reduced the true contact resistance is masked by the line resistance and the curves level off. The flat portions of the curves therefore are not true contact resistance and we have qualified the ordinate label by placing "contact resistance" in quotation marks. Even the heavy plated lines show the impact of line resistance although only at much lower sheet resistance levels. True contact resistance would be represented by a line extrapolated through the points of inflection of a family of curves with different lines resistances. These curves indicate that below sheet resistance values of about 100 ohms/square, which includes all practical solar cells, the contact resistance is not a significant factor. They also indicate that line resistance is of overriding significance. Use of the double diffusion process solely for the reduction of contact resistance, therefore, is not justified. The contact resistance on the

$50 \mathrm{ohms} / \mathrm{square}$ open area would be higher than on the low resistance mesas, but not significantly so.

The relative significance of $n$-layer resistance, contact resistance and line resistance can now be shown using typical design data and the contact and line resistance calculated above.

If we consider a "unit field" surrounding one grid line only, the n-layer, contact, and line resistances are given by:

$$
\begin{aligned}
& R_{n}=\frac{R_{s} d}{6 L} \\
& R_{c}=\frac{r_{c}}{W L}
\end{aligned}
$$




$$
R_{1}=\frac{r_{m} L}{2 W}
$$

where $\quad R_{S}=n$-layer sheet resistance $=50 \mathrm{ohms} /$ square

$d \quad=$ open space between grid lines

$\mathrm{L}=$ length of grid line $=400 \mathrm{mils}=1.016 \mathrm{~cm}$

$r_{c}=$ true contact resistance $=.01$ milliohm $/ \mathrm{cm}^{2}$

$W \quad=$ line width

$r_{m}=$ line sheet resistance $=1 \mathrm{milliohm} / \mathrm{square}$

Using the typical constant values shown above and a center to center grid spacing of 10 mils the following values can be calculated for the various grid line widths shown:

W

$\begin{array}{lcl}\text { mils } & \mathrm{m} & \mathrm{cm} \\ .7 & 17.78 & .001778 \\ .5 & 12.7 & .00127 \\ & 10.0 & .001\end{array}$

d

$\mathrm{cm}$
$\mathrm{R}_{\mathrm{n}}$

m

179

188

192
$\mathrm{R}_{\mathrm{C}}$

m

5.5

7.8

9.8
$\mathrm{R}_{\mathrm{l}}$

$\mathrm{m}$

In each case the most significant element of the series resistance is the line resistance and this is the area where the greatest improvement opportunities exist.

\section{Junction Leakage on Textured Cells}

Leakage across the junction, manifested by a slope on the horizontal part of the IV curve, occurred occasionally on some cells. We investigated this problem to determine whether or not it was inherent in the texturization process itself or caused by some peripheral process step. Failure analysis procedures were used to trace the cause of the leakage to cell cleaning steps, which can be more critical on some harder to clean types of textured surface than on others. The leakage was not attributable to the texture etch processing itself. Two changes in process flow were implemented to correct the problem and no further recurrence has been experienced since these changes were instituted.

SEM analysis showed the presence of some foreign material on suspected cells (see Figure 14) and Auger Electron Spectroscopy (AES) and Secondary Ion Mass Spectroscopy (SIMS) analysis were used to determine the character of the contaminant material. These data were then correlated with cell behavior and process history. The presence of contaminants appeared to be related to the 
fineness or coarseness of the texture and was therefore related to the cleanability of the various surfaces. Our final conclusion from these tests is that two separate potential sources of leakage contamination exist. These are 1) residual photo resist and 2) residuals from the J-100 photo resist removal processing. The first type, residual PR, may be caused by higher than necessary post bake inadvertently used on those samples. This defect shows up as residual carbon in the AES line scans. The carbon probably reacts with the silicon in subsequent high temperature processing to form SiC. This source of contamination can be prevented by minimum PR post bake and by adding peroxide in supplemental cleaning to eliminate the carbon. Type 2 residuals from $\mathrm{J}-100$ appear as $\mathrm{Mg}$ and $\mathrm{Cl}$, plus carbon. The same measures as for type 1, plus more thorough J-100 rinses are effective in preventing type 2 contamination.

However, the most important process change used to avoid contamination problems was the application of the passivation/AR oxide coating early in the process flow. We had formerly applied the AR coating by CVD as a last step after electroplating. The change to a thermal oxide grown after diffusiuil was instituted primarily to improve the surface recombination velocity. Nevertheless, its institution early in the cell processing provides passivation protection through all the subsequent photo resist processing. This change is probably the single most important element in avoiding contamination induced leakage.

\section{Texture Etch Process Control}

Our early texture etch process utilized a 1:1 hydrazine: water etchant employed at $90^{\circ} \mathrm{C}$. While reasonably good results were achieved with this process a number of observations made us feel that process control was not adequate. In the first place, fresh etchant did not seem to etch well until "primed" with some dissolved silicon. Also, there seemed to be an incubation period during which no pyramids appeared and occasionally only a portion of the wafer would initiate pyramids at one time followed by other sections which textured later. The result was an irregular "blotchy" appearance usually coupled with a much longer total etch time for complete texturization. We suspected that the latter effect might be related to contamination or to the prior processing the water received, especially slnce we had observed some differences in the way diffused wafers etched as compared to non-diffused wafers. We therefore investigated the above variables and now have a controllable process in which pyramid initiation is very positive and predictable, texturization is consistently uniform across the wafer and, because of this consistency, the etch depth can be held constant. The latter proves to be an important feature in establishing a consistently high cell voltage. The following is a detailed account of the texture etch process investigation:

A test matrix was first devised to evaluate the etching behavior of 1) an "as received" wafer, 2) an "as received" wafer, with a grown oxide that has been etched with a gird line mask, and 3) a heavily diffused wafer also with an etched oxide mask. These three wafer types were etched in 1:1 hydrazine for one, two, three and four minutes. Results of this test are shown in Figures 15, 16, and 17 as SEM photographs.

Inspection of the SEM photographs shows that as the etching process begins it is essentially isotropic with only a few (111) planes etching slowly, that is, only a few pyramids appear. The smooth areas between peak are etching faster than the textured areas. Fresh etchant that has not been primed with silicon behaves 
in a similar manner, forming a smooth surface; the etch rate is about $2 X$ the etch , rate when texturizing.

A key feature of this experiment is the inclusion of the selectively etched mesa pattern. The height of the mesa serves as a reference height of the original wafer surface. Without this reference it is difficult to determine the differential etch rate and to measure the average depth of etch. For example, examination of the SEMS of the unpatterned wafers does not reveal any information about the depth of the etch. Examination of the patterned wafer SEMS shows that about three minutes was required to form a uniformily covered pyramid field in all cases, but the total depth of etch from the original surface varies considerably. The phosphorus diffused wafers have a greater average depth of etch than the non-diffused wafers (see Figure 18, which summarizes the etch test) indicating that the etch is not as selective on this material and therefore behaves more like an isotropic etch. This is also shown by the undercutting of the lines while the non-diffused wafers are undercut only slightly.

Approximately three minutes in $1: 1$ hydrazine $990^{\circ} \mathrm{C}$ is required to achieve a uniform coverage of pyramids. This is a very short time for good process control and any delay in the initiation period (such as caused by fresh etchant) affects the total etch time. Nonuniformity results when different areas on the same wafer do not initiate at the same time. Accordingly, we have examined conditions which tend to favor pyramid initiation. The present 1:1 hydrazine high temperature $\left(90^{\circ} \mathrm{C}\right.$ refluxing) etch process was initially developed as an anisotropic etch for geometries such as might be employed for isolation in IC devices. For such a purpose, the spontaneous initiation of pyramids is a defect and the incubation period is actually desirable. Our own observations supported by a literature review indicates that lower etch temperatures favor pyramid initiation al though the etch rate is much reduced.

A room temperature etch test was, therefore, conducted on diffused wafers to evaluate uniformity of pyramid initiation, etch times required, etch rates achieved and pyramid size. The SEM micrographs in Figures 19 and 20 show the results achieved in the test at successive etch times to a total of 60 minutes of etching. Table 1 shows the etch depth and line width reduction. After five minutes the pyramid initiation was complete and uniformly distributed over the wafer. From 5 to 15 minutes was a period of rapid pyramid growth and complete filling of the open spaces. Pyramid growth continued to the end of the test (60 minutes), but at a much slower rate. Pyramid size is estimated from the SEM photographs at about $\mathrm{l} \mathrm{m}$ after 15 minutes and from 2 to $3, \mathrm{~m}$ after 60 minutes. As noted in Table 1 practically no undercutting of line width occurs in the 15 minute etch and an average etch depth of $2, \mathrm{~m}$ is developed. The main feature of interest in this test is the uniform and rapid (for this temperature) pyramid initiation. This is attractive as a first step in a two step process with pyramid growth to $10 \mathrm{~m}$ conducted in the second step at $90{ }^{\circ} \mathrm{C}$. The initiation period could then be stablilized and good process control established over this critical phase. The high temperature etch is needed to develop adequate pyramid size in a reasonable time.

A preliminary test of the suggested process was conducted by etching at room temperature for 15 minutes for pyramid initiation, followed by 2 minutes and 5 minutes additional at $90^{\circ} \mathrm{C}$ for pyramid growth. Partial results are shown in Table 2 which shows the average etch depth. The total etch depth $(4 \mathrm{~m})$ is about equivalent to that achieved in 60 minutes at room temperature. Pyramid coverage 
and uniformity is actually adequate after 2 minutes (d $90^{\circ} \mathrm{C}$, which results in only $2.5 \mathrm{~m}$ average etch depth.

The simplicity of ambient etching, the degree of control attainable and the consistent uniformity of the texture produced, plus the small amount of material removal prompted us to examine the ambient etch as a complete texturization process. A group of wafers was processed which received only a 15 minute ambient etch for texturization. This ambient etched group was consistently higher in open circuit voltage; .59 to .61 volt as compared to .57 to .59 volt for the normally processed good cells. One possible explanation for this improved voltage might be the fact that the etch is very shallow. Only about $2 \mathrm{~m}$ of material is removed which is barely enough to remove the first heavy diffused layer. Possibly, the first heavy phosphorus diffusion getters impurities from the immediate vicinity so that when the impurities are removed in the etch along with the junction, the second n-layer can be built In this purified regiur. We suspect that in normal deep etch processing ( $4 \mathrm{~m}$ depth) the purified gettered region is removed as well so that the second junction is built in essentially original bulk material.

However, the ambient etch used by itself, while very consist =nt in pyramid initiation, nevertheless does not always produce a good visual appearance. In contrast, the two step process, even with only a two minute etch at $90^{\circ} \mathrm{C}$ consistently textures evenly to a controlled etch depth. The total etch depth in this case is only slightly increased over the one step ambient etch. We therefore standardized on the two step process. $V_{o c}$ has continued to remain high on all these shallow etched parts in keeping with our earlier observations on ambient etch only parts. Small variations in $V_{o c}$ do not seem to be a function of the small part to part variations in etch depth, so the process is not critical within this depth range. From a visual standpoint, neither step in the process is critical. The parts do not always have a good vlsual appearance aller the 15 minute ambient etch, but this does not seem to affect the find appearalice dl all. A constant, timed process is therefore practical without in-process inspection of parts. Furthermore, the lifetime of the high temperature bath is much extended. Apparently, the silicon content affects the pyramid initiation more than the etch rate. The ambient bath requires more frenuent replenishment, but because the material removal is much smaller than formerly, the lifetime is also extended over the straight $90^{\circ} \mathrm{C}$ process. The spent ambient bath can be saved for use at $90^{\circ} \mathrm{C}$ where it is still effective.

Both the ambient and high temperature baths require some initial priming of the fresh solution for consistent process control. The same procedure is used for both baths and consists of etching one wafer for 30 minutes at $90^{\circ} \mathrm{C}$. in $200 \mathrm{ml}$ of sulutivin.

The final standardized process details are as follows:

Ambient bath:

High temp. bath: l:1 hydrazine:water, room temperature, 15
Lifetime approx. 500 wafer-minutes/ $200 \mathrm{ml}$

1:1 hydrazine: water, $90^{\circ} \mathrm{C}, 2$ minutes. Lifetime approx. 150 wafer-minutes $/ 200 \mathrm{ml}$ 


\section{Task 3.0 Production of Sample Cells}

The option of combining both task samples on the same unit was exercised so that the full impact of the combined benefit to be derived from these two processes could be derived. The cells are supplied as 25 double cells which will facilitate test set up. They may be scribed and broken if single cell testing is desired. Testing of cells was conducted in a special facility set up for our use. A schematic of the test facility is shown in Figure 21. As shown, the test facility consists of 1) an XM-300, $25 \mathrm{Kw}$ high pressure $\mathrm{Xe}$ arc lamp source module with its $\mathrm{X}-200$ controller, 2) a cell mount and cooling block with an $\mathrm{N}^{2}$ gas heat exchanger cooled by liquid $\mathrm{N}^{2}, 3$ ) a bank of 20 ampere power supplies, and 4) a Compucorp minicomputer for control and data acquisition. An important feature of the system software is the iterative measurement of the cell's I/V data which is used for signal averaging to enhance signal to noise ratio. This eliminates the jitter caused by fluctuations in the $\mathrm{Xe}$ arc lamp output. With this test facility, large area cells such as those described in this report can be tested at concentrations in excess of 200 suns. 


\subsection{SUMMARY-RESULTS AND CONCLUSIONS}

The high aspect ratio electrode has been shown to be a feasible concept with processes developed for fabrication of .7 mil wide by .7 mil high electrodes. The use of pulse plating techniques in maintaining a near vertical edge profile has been demonstrated. By far the most impressive achievement in this area is the line conductivity improvement. Pulse plating conditions were established which deposit silver metal with conductivity equivalent to the bulk silver properties. Pulse lengths must be extremely short to optimize this effect and consequently, care must be taken not to exceed the peak current or voltage capabilities of the plating supply.

The selective etch process has been shown to have a major advantage in processing of fine line geometries. Since no lines are applied to textured areas and the original polished wafer surface retains its original flatness, the llne resolution limits are comparable to IC processing, with similar visibility in the alignment step.

Contact resistance has been shown to be a very small part of the total resistance on $n$-layer sheet resistances below 100 ohms/square. Therefore, the double diffusion step is not justified for this purpose alone. However, the double diffusion step was retained because it ensures against junction shorts, enhances the high temperature resistance of the cell and getters impurities from the top surface. The selective texturization process was absoived of any direct responsibility for junction leakage problems, which were shown to be related to wafer cleaning after photo resist operations. Process flow changes were developed to passivate the cell surface at the diffusion step, thus obviating any critical cleaning steps and eliminating the necessity for a later AR coating process.

Finally, the texturizing etch process sequence itselt was developed tor good consistency and process control. Conditions which govern the Inltatlon of pyramid growth were evaluated and a two step procedure established which separately controls pyramid initiation and growth. The total etch depth was reduced, thus extending the etch bath life. But of greater significance, the controlled etch depth produces an improved $V_{o c}$, presumably from gettering of impurities in this zone.

Final cell tests at concentration have verified the combined effect of the high electrode and selective texturization processes. The efficiency fall off that normally occurs as a result of limiting serles reslstance has been much reduced. A typical efficiency vs. concentration plot, as in Figure 22, shows a gradually rising curve which levels off towards the high end, but is still increasing above 120 suns. This curve represents the best cell measured to date. Peak efficiency exceeds 16\%, however, the one sun efficiency of this cell design is low. If a higher one sun efficiency cell were employed with these two processes it is expected that a more impressive peak efficiency would be obtained. The most significant improvement demonstrated is the prevention of the efficiency fall off at high concentration in a large area cell. 
Table 1. Selective Texturization Etch of Diffused Wafers in 1:1 Hydrazine at Room Temperature

\begin{tabular}{|c|c|c|}
\hline Etch time $(\mathrm{min})$ & $\begin{array}{l}\text { Etch depth, average, } \\
\text { light-section microscope }(\mu \mathrm{m})\end{array}$ & $\begin{array}{l}\text { Line width, mask } \\
1.5 \text { mil (mil) }\end{array}$ \\
\hline 15 & 2 & 1.5 \\
30 & 3 to 3.5 & 1.4 \\
45 & 3 to 3.5 & 1.4 \\
60 & 4 & 1.3 \\
\hline
\end{tabular}

Table 2. Selective Texturization Etch Using a Two-Step Process in 1:1 Hydrazine

\begin{tabular}{|c|c|c|}
\hline Etch time $(\mathrm{min})$ & Temperature $\left({ }^{\circ} \mathrm{C}\right)$ & $\begin{array}{l}\text { Cumulative etch depth, } \\
\text { average, light-section } \\
\text { microccopo }(\mu \mathrm{m})\end{array}$ \\
\hline 15 & 25 & 2.0 \\
Plus 2 & 90 & 2.5 \\
Plus 5 & 90 & 4.0 \\
\hline
\end{tabular}




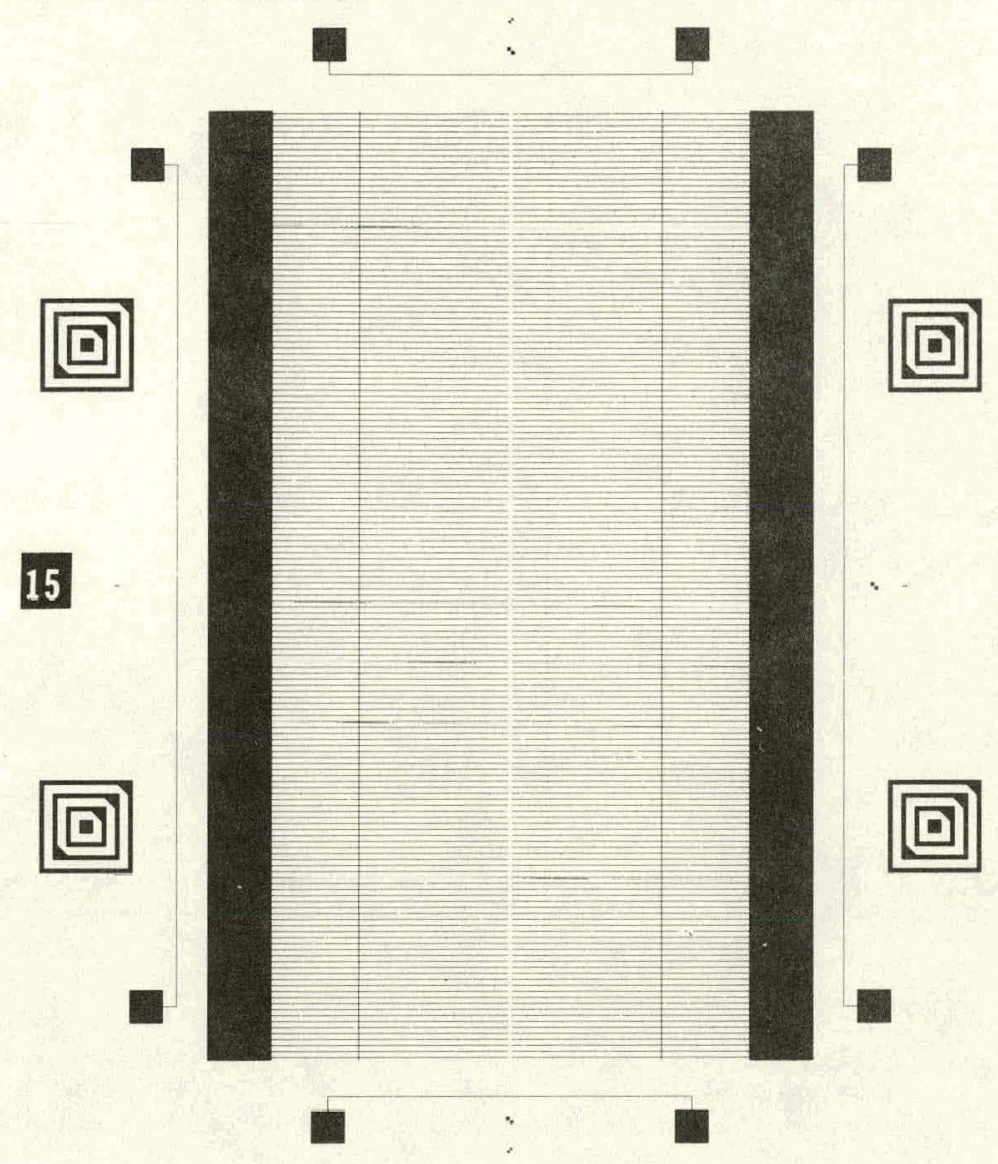

Figure 1. Dual-Cell Design With Test Patterns

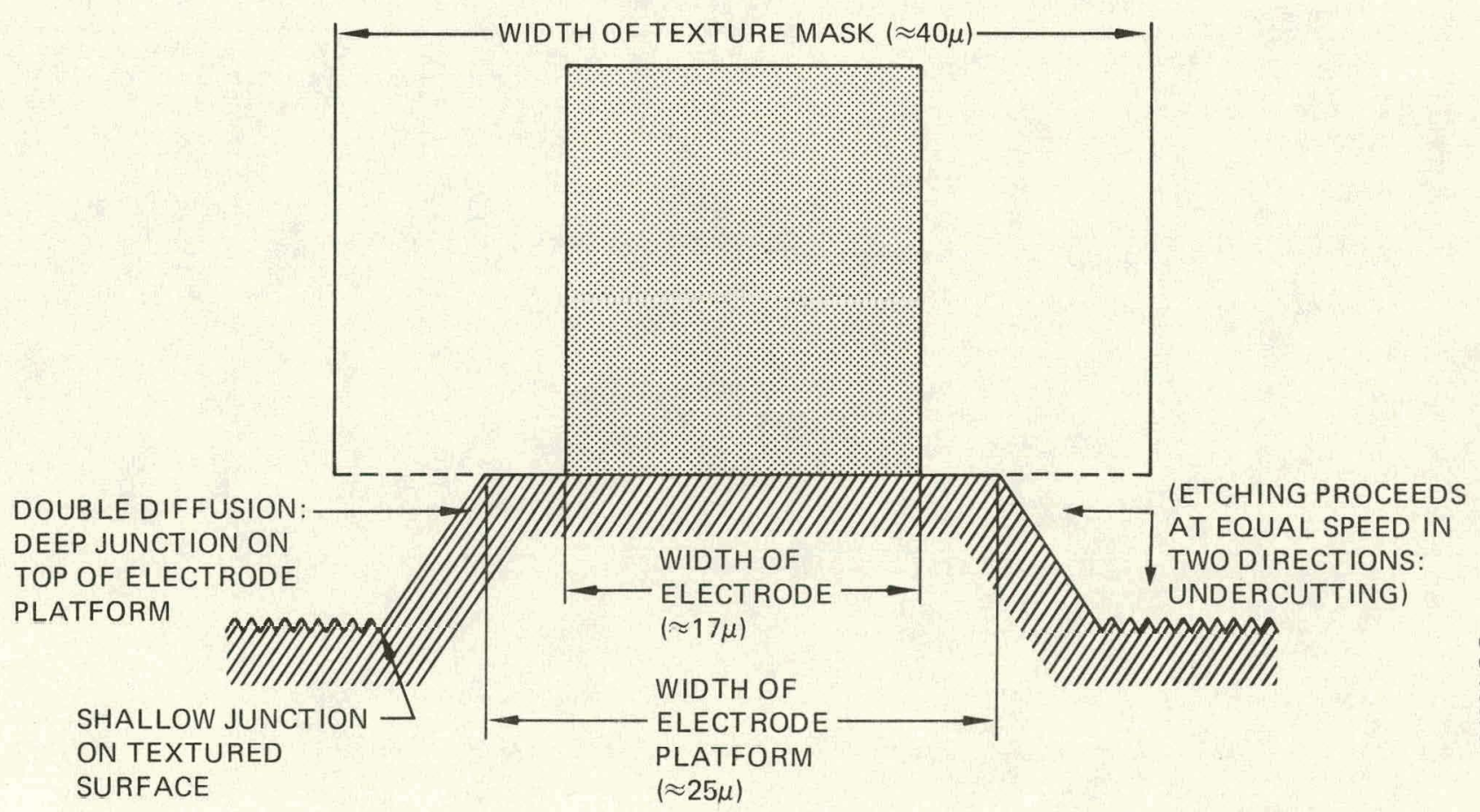

Figure 2. Collector Electrode on Face of Selectively Texturized Concentrator Cell 


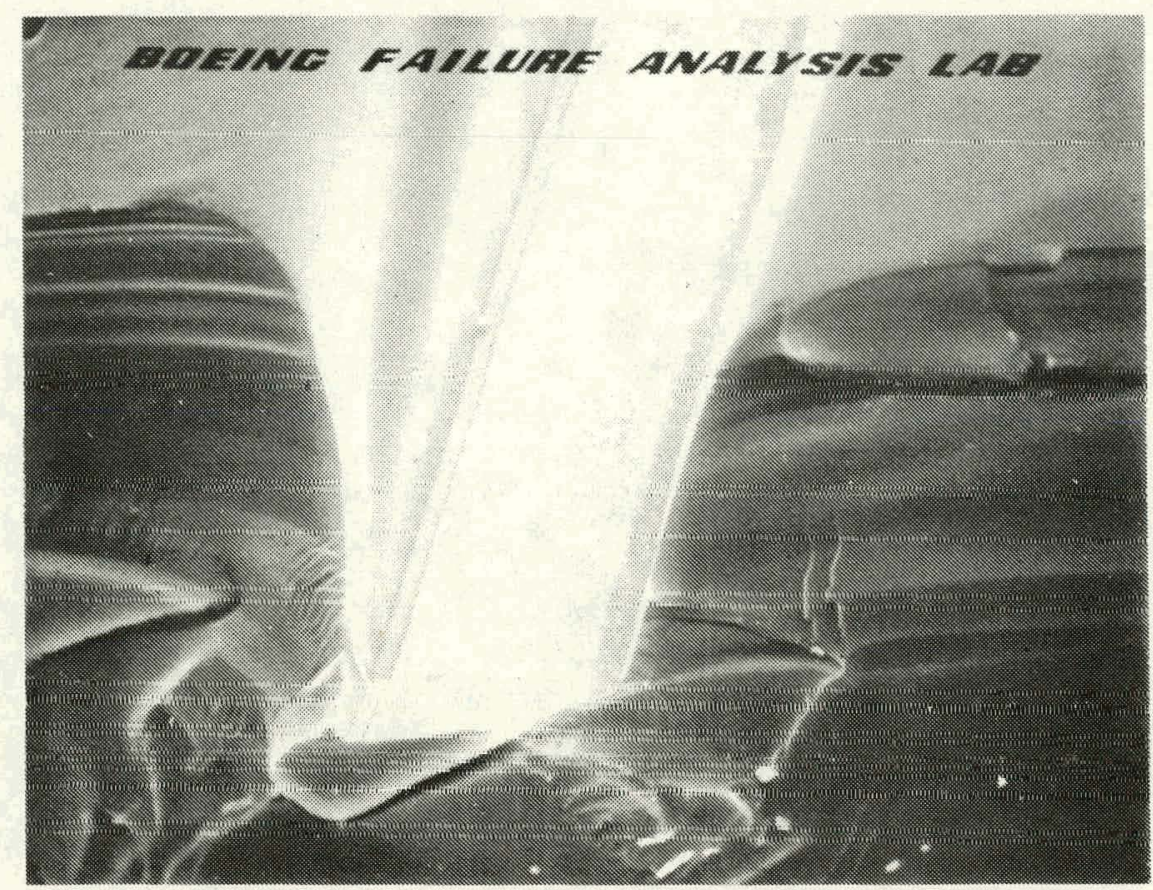

Figure 3. SEM Photo of a Cross-Sectional View of a Resist Groove $\left(2,000 x ; 60^{\circ}\right)$

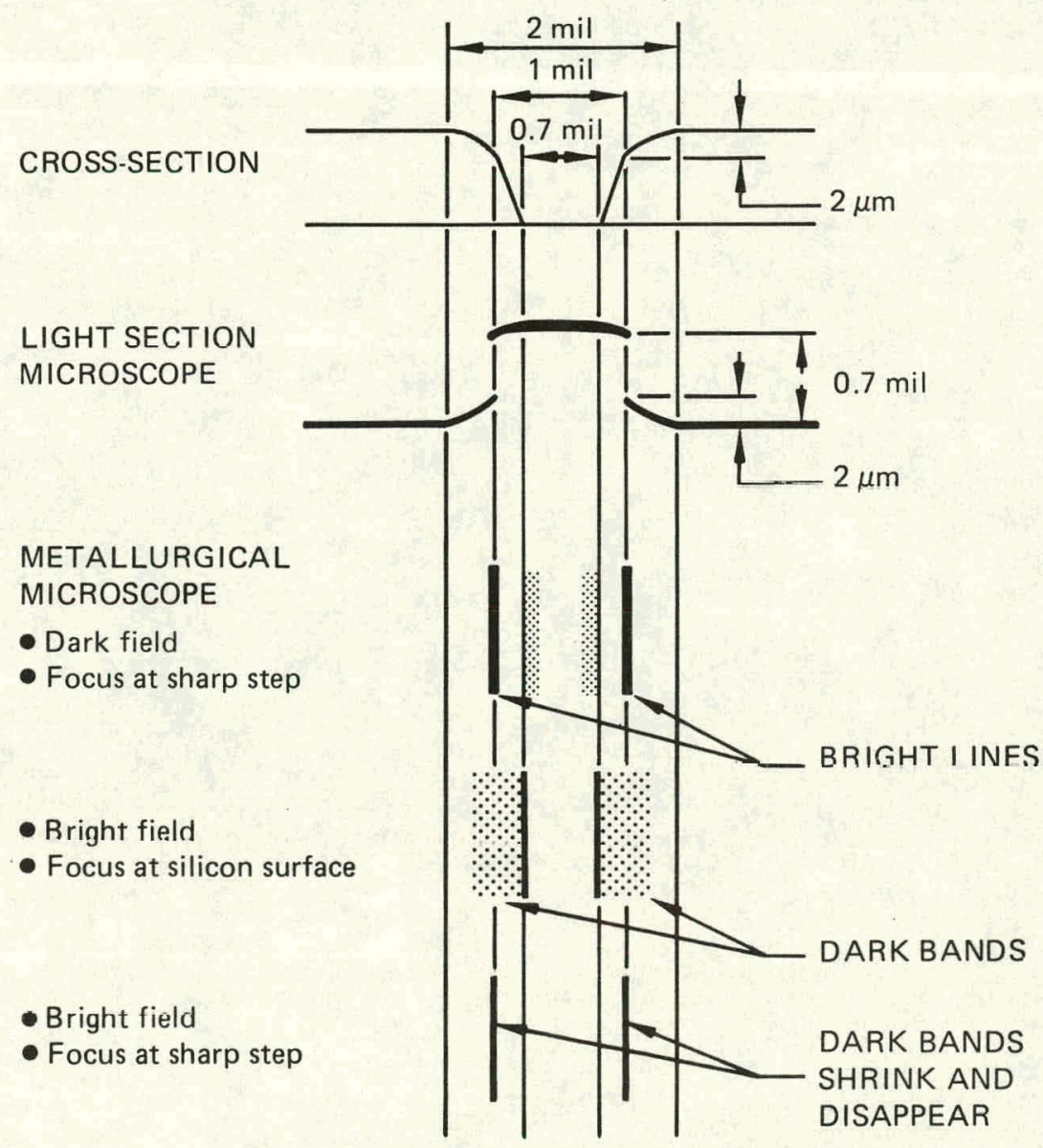

Figure 4. Resist Profile Characterization 


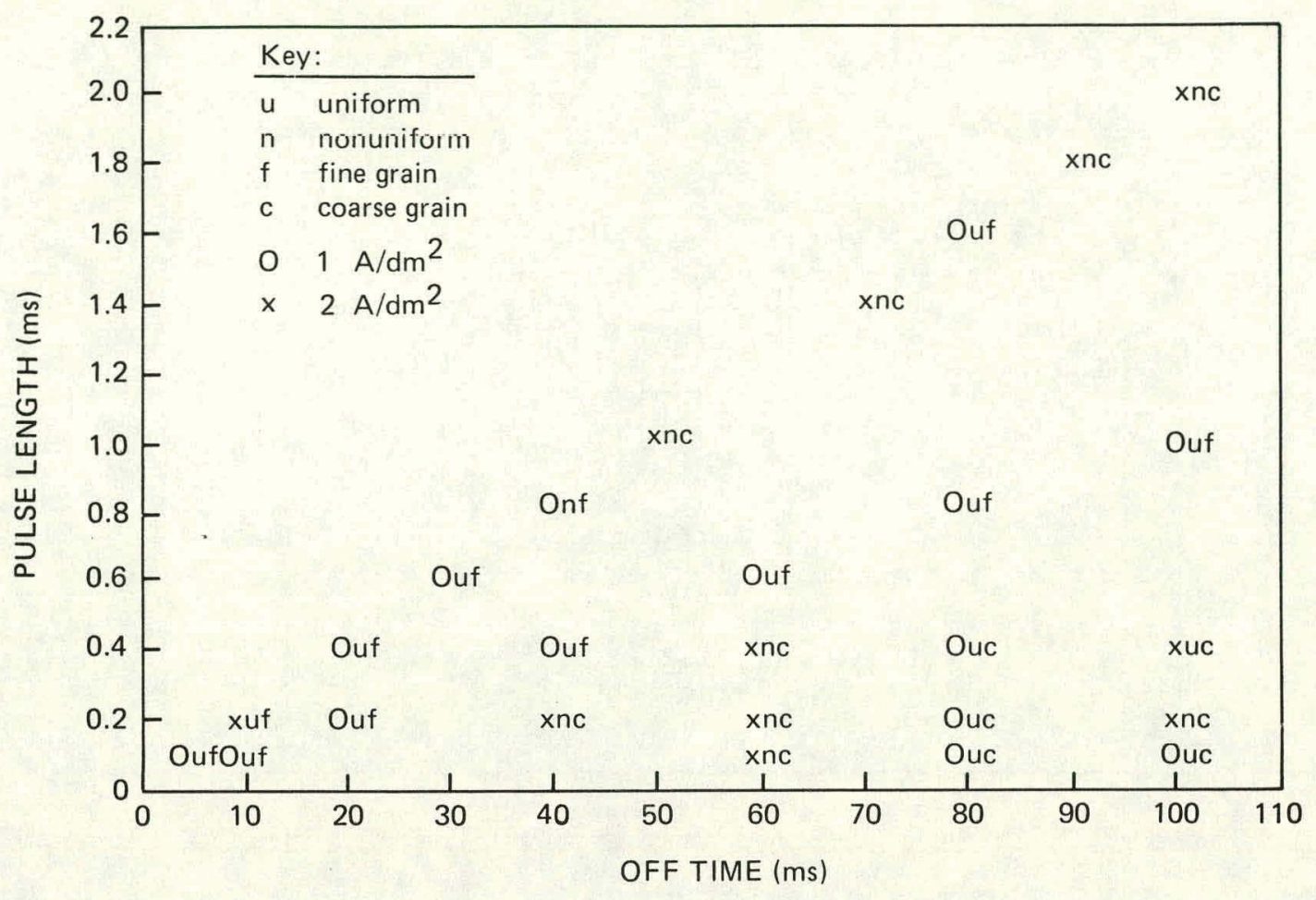

ণ্ণ

Figure 5. Pulse-Plating Test Matrix

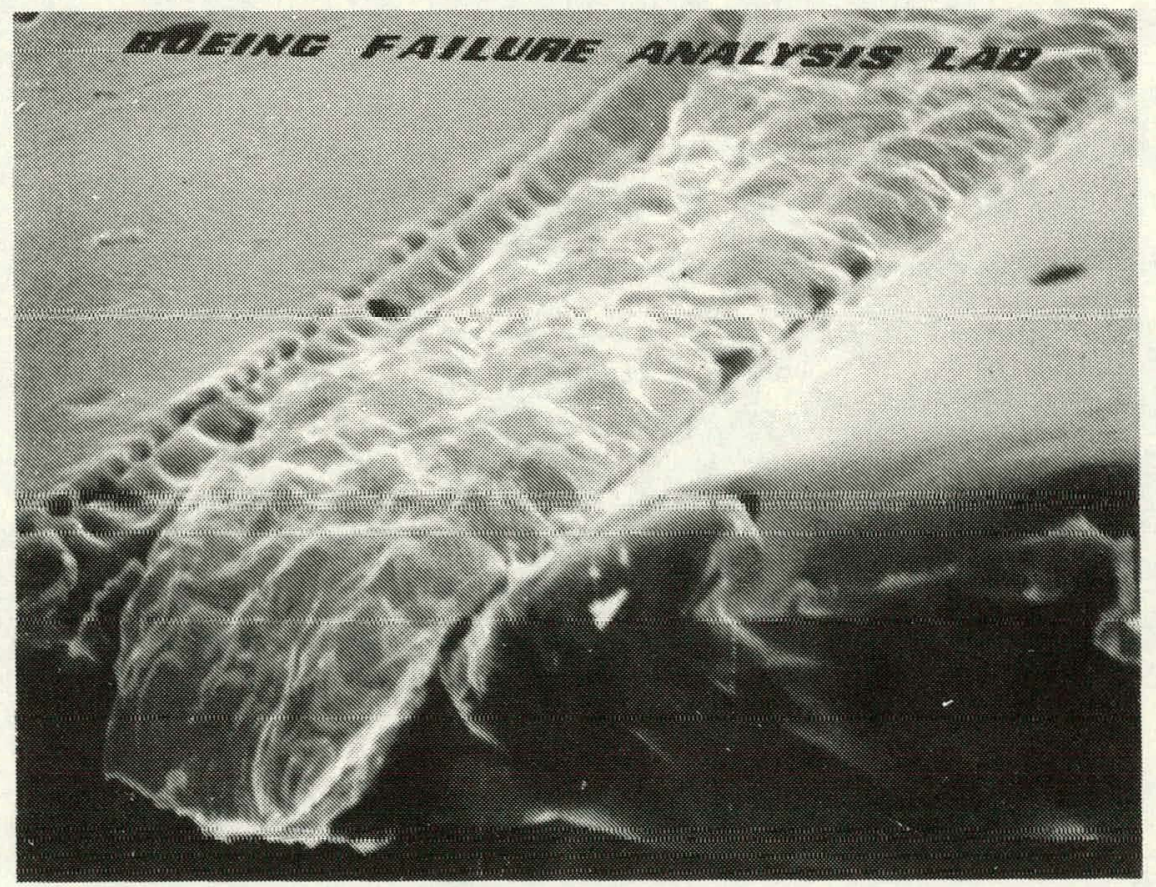

Figure 6. SEM Photo of a dc-Plated Line With Resist Mask $\left(2,000 X ; 45^{\circ}\right)$ 


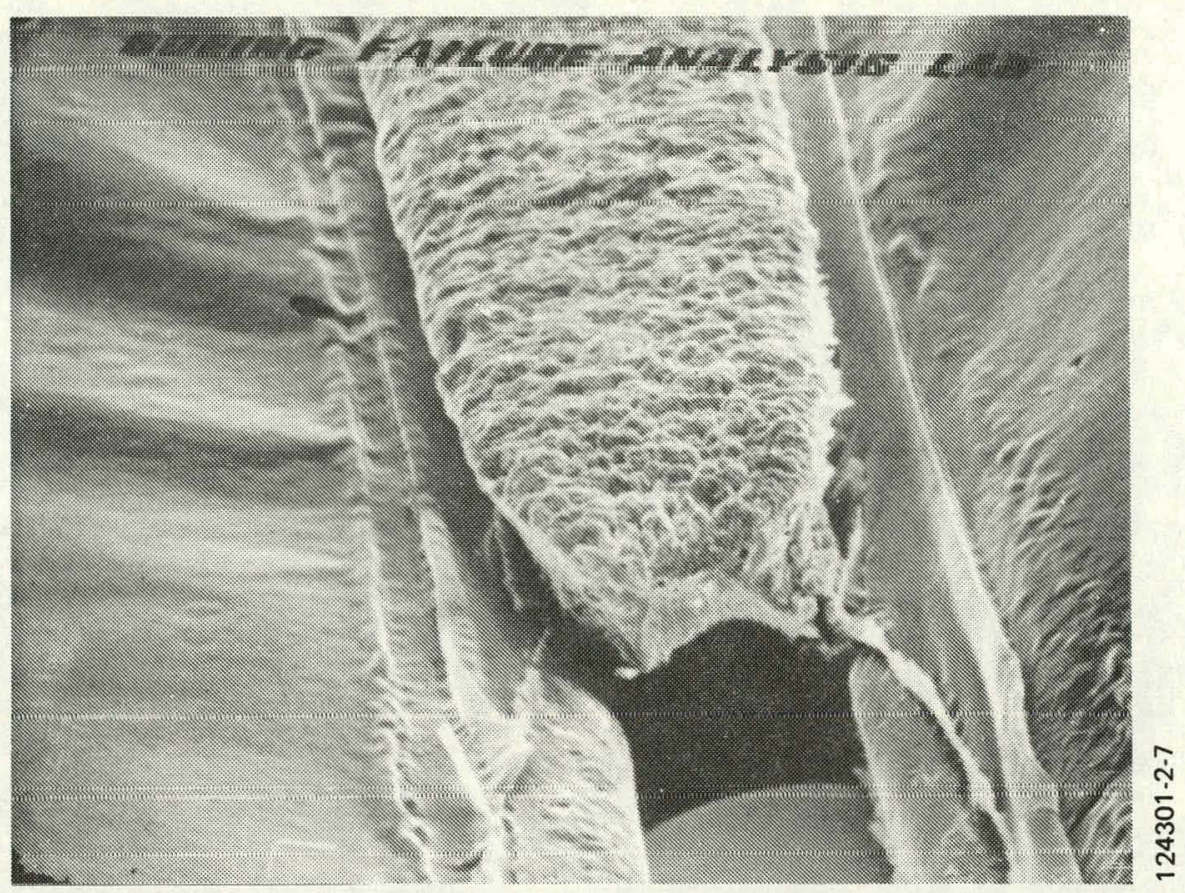

Figure 7. SEM Photo of a Pulse-Plated Line With Resist Mask $\left(2,000 X ; 45^{\circ}\right)$

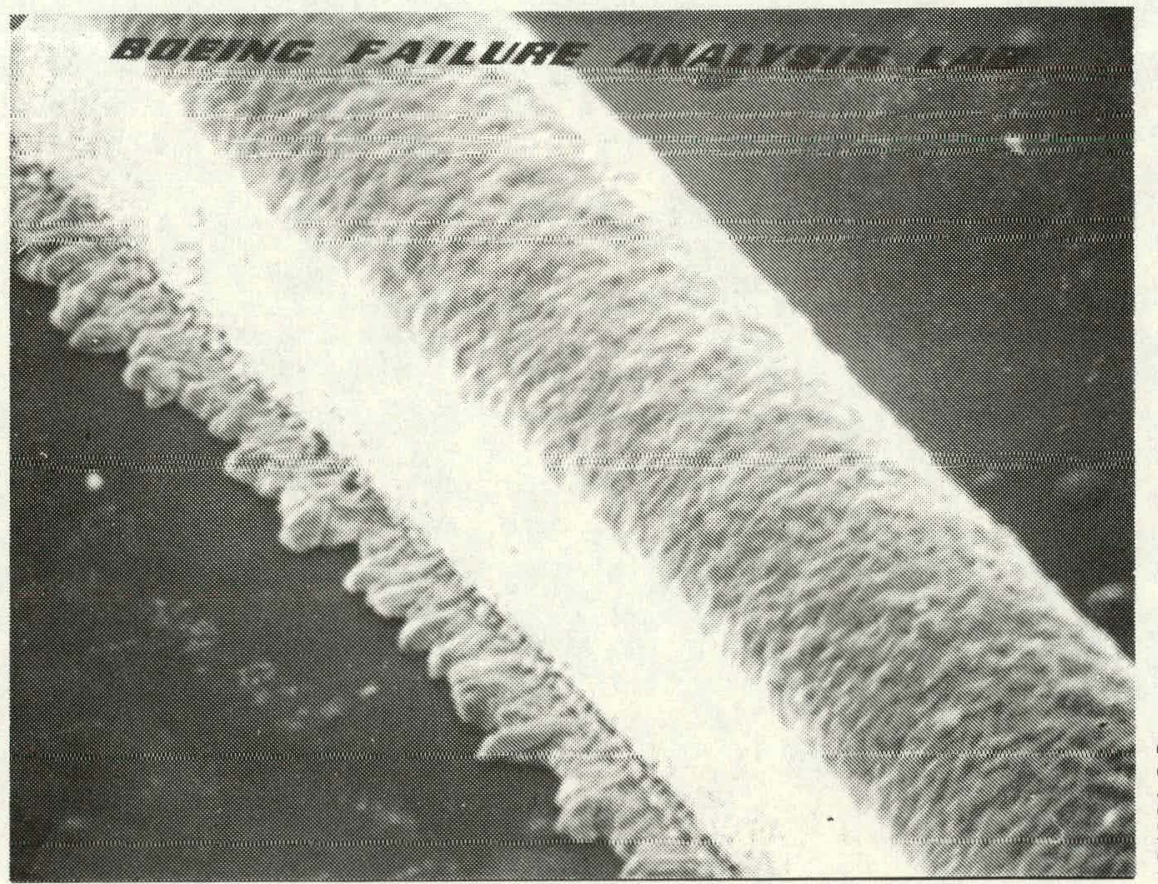

곰

Figure 8. SEM Photo of a Pulse-Plated Line With Resist Removed $(2,000 X)$ 


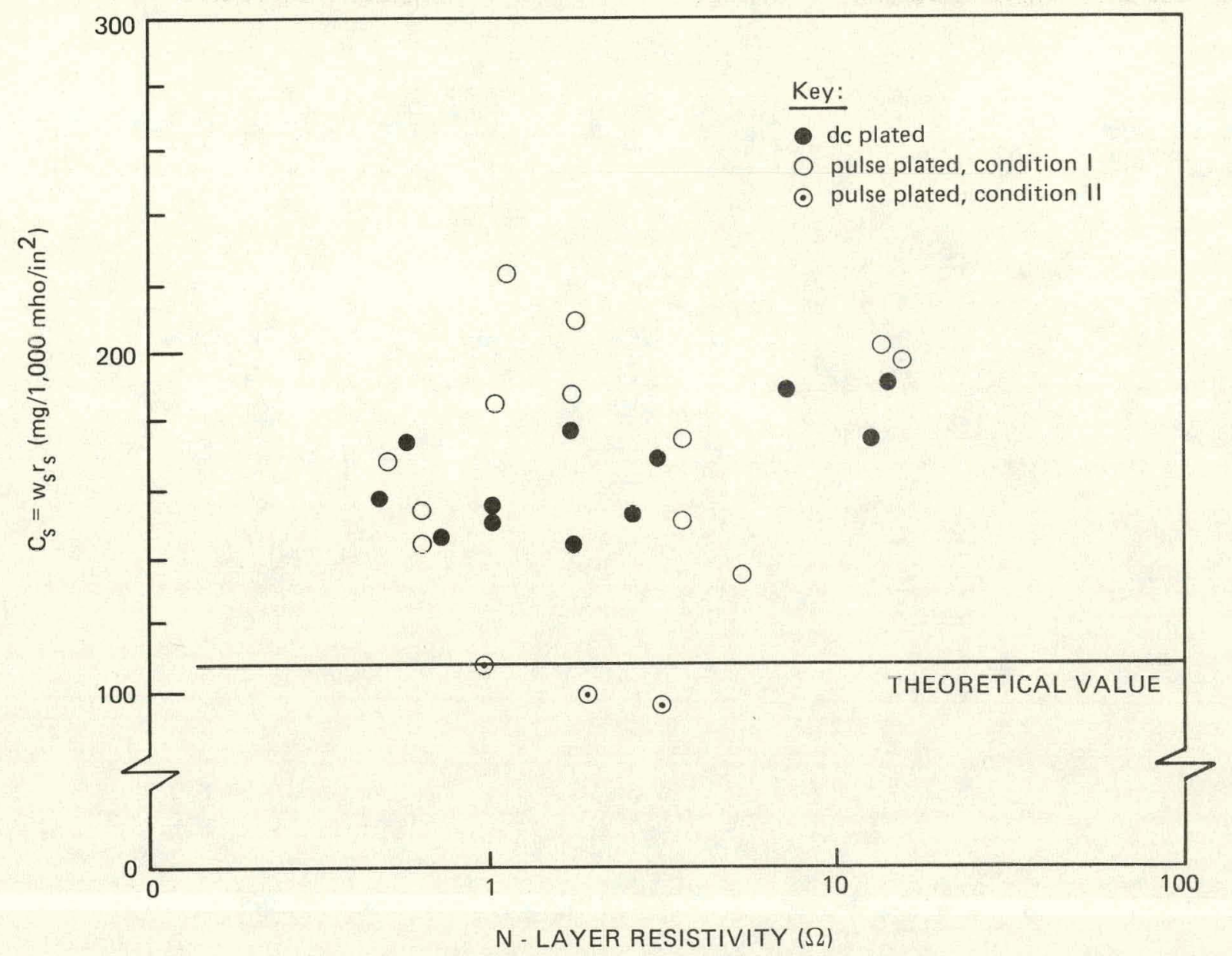

Figure 9. Conduction Efficiency Parameter, $C_{S^{\prime}}$ for Various Plating Conditions

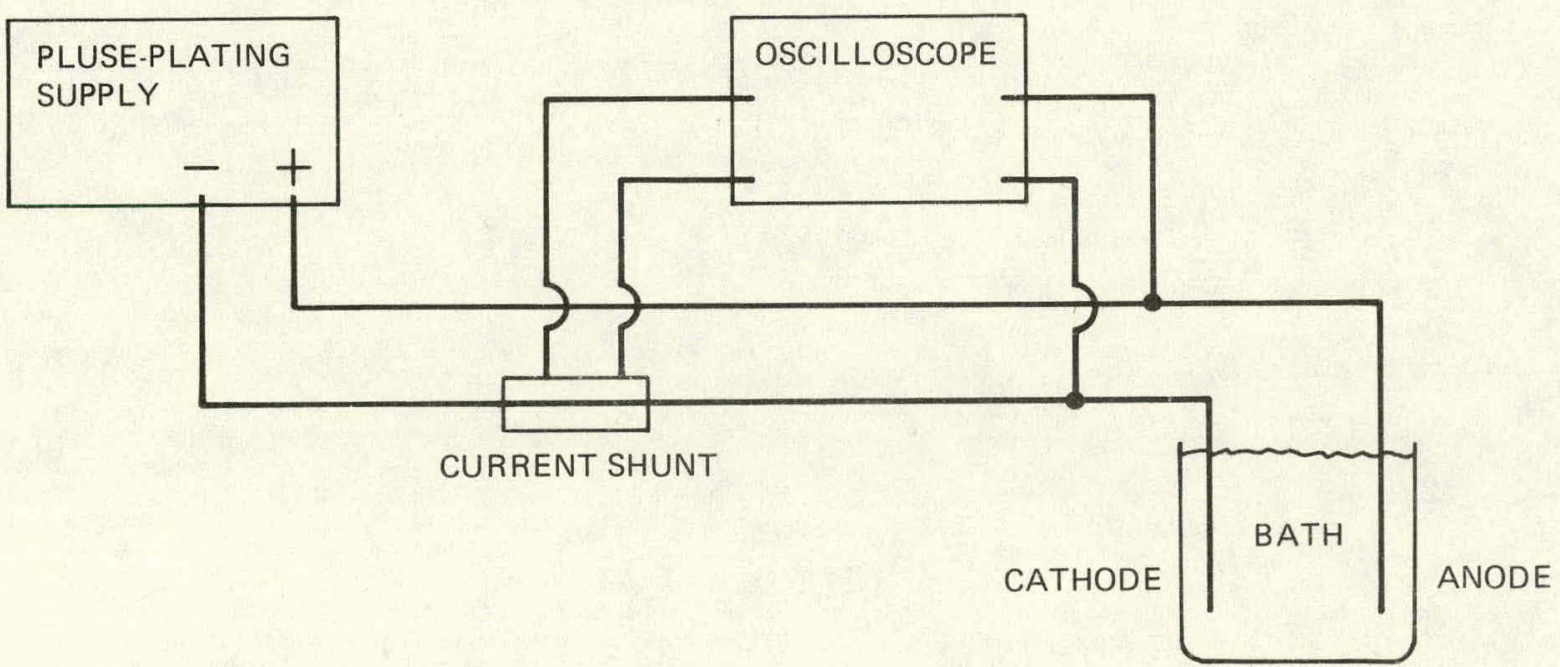

Figure 10. Apparalus for Pulse-Plating Current and Voltage Monitor 

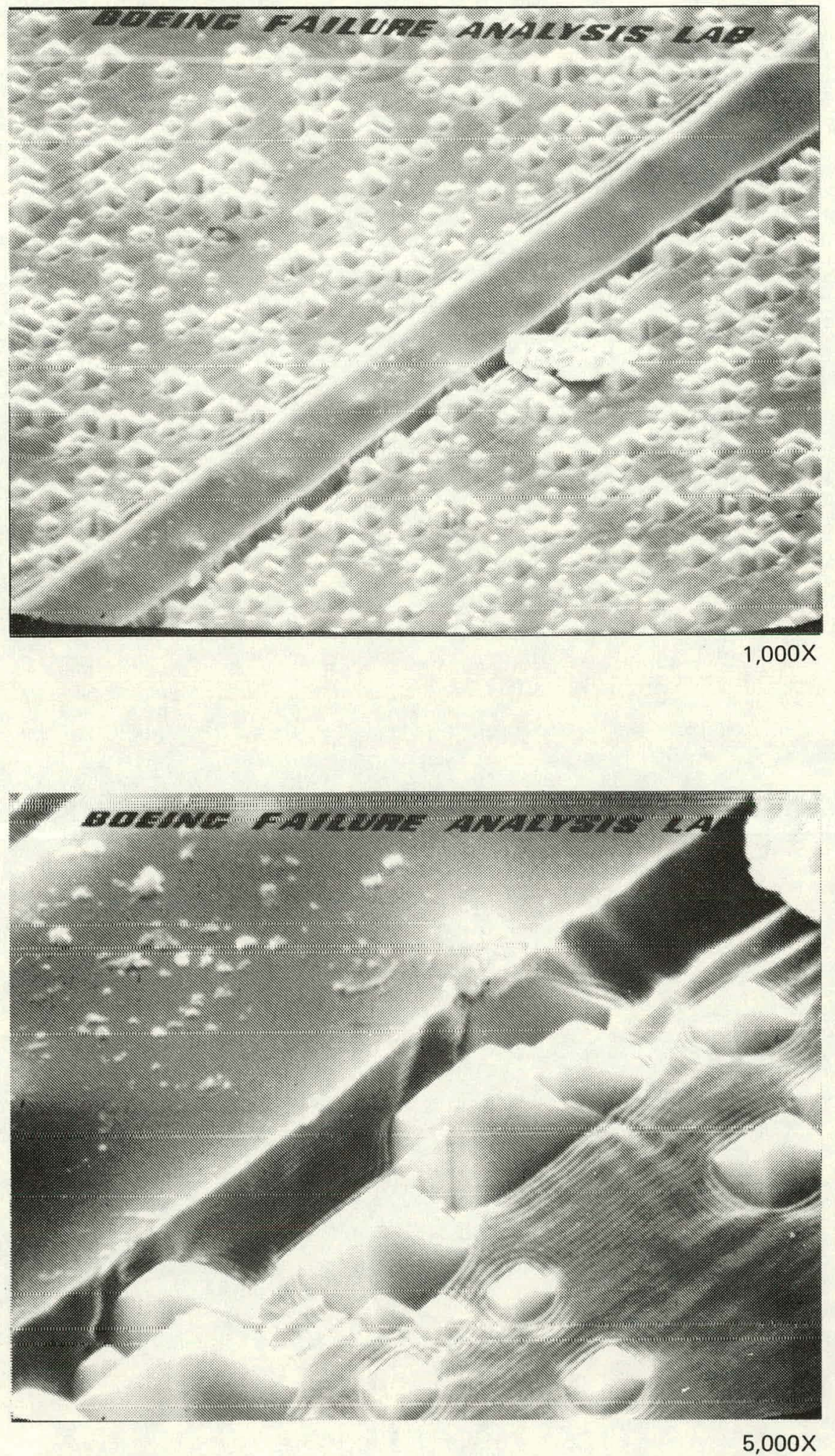

Figure 11. SEM Photos of Photo-Resist Lines on a Textured Surface 


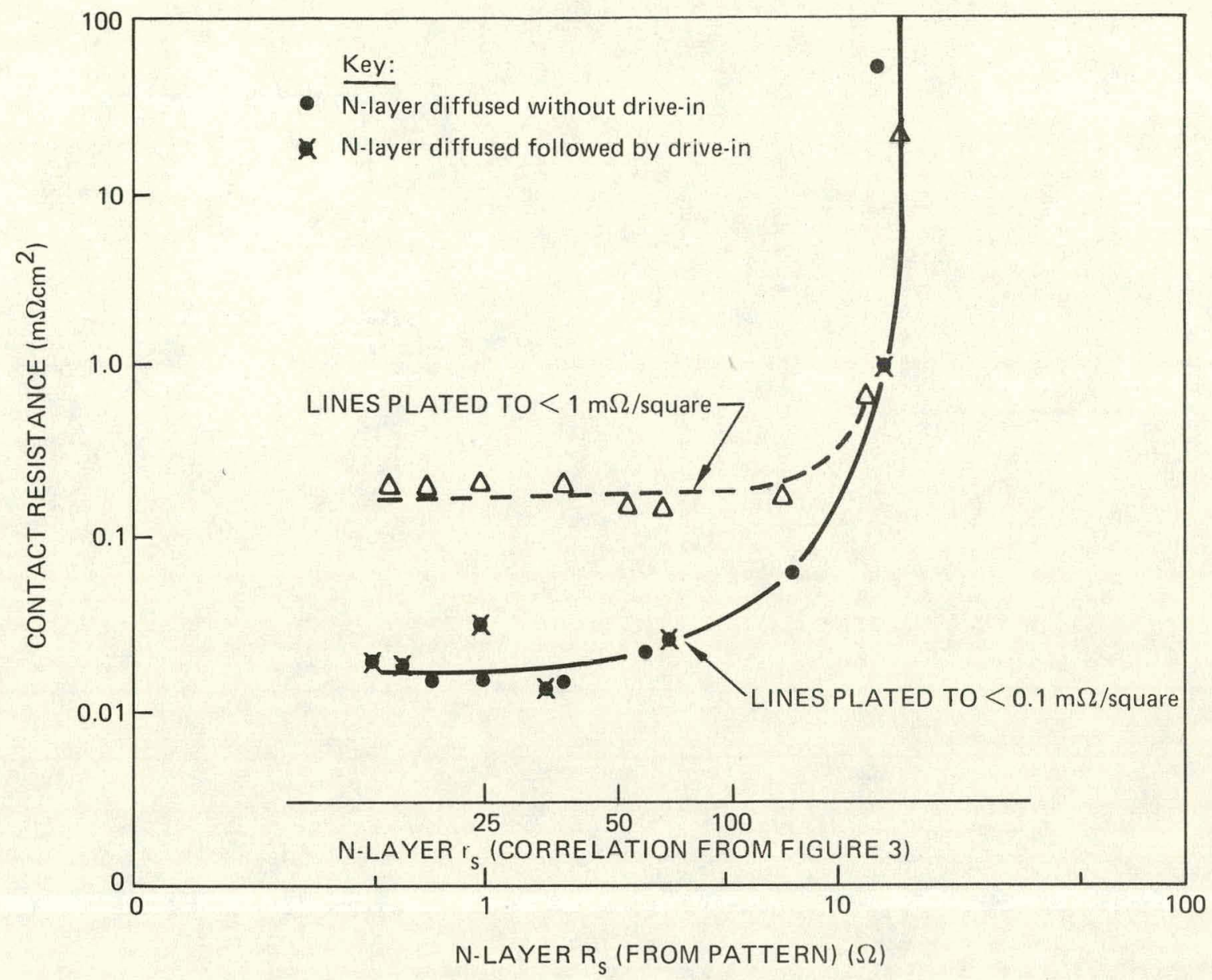

$\frac{N}{\grave{1}}$

Figure 12. Contact Resistance as a Function of N-Layer Resistivity

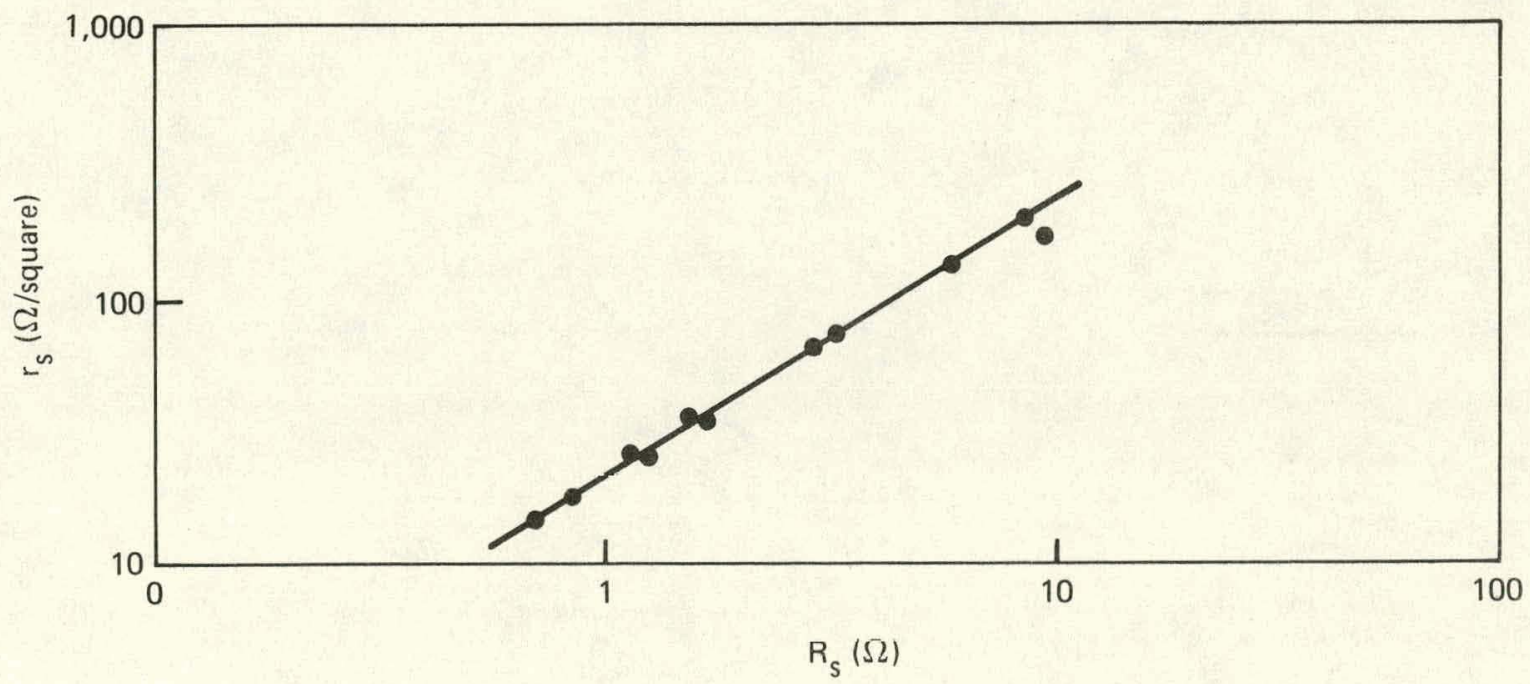

ণัণ

Figure 13. Correlation Between $\mathrm{N}$-Layer Resistivity $r_{s}$ and Test-Pattern Readings $R_{S}$ 
SAMPLE 2

SEM

$1,200 X$

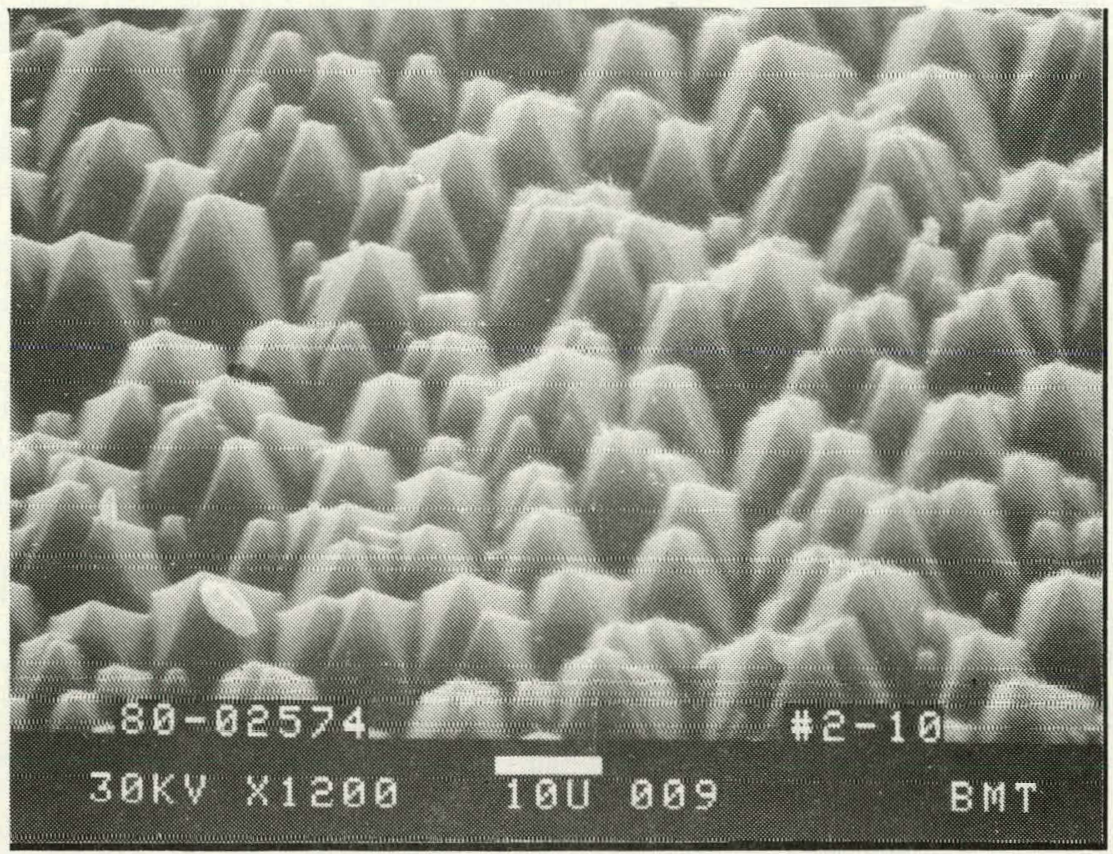

SAMPLE 2

SEM

$12,000 X$

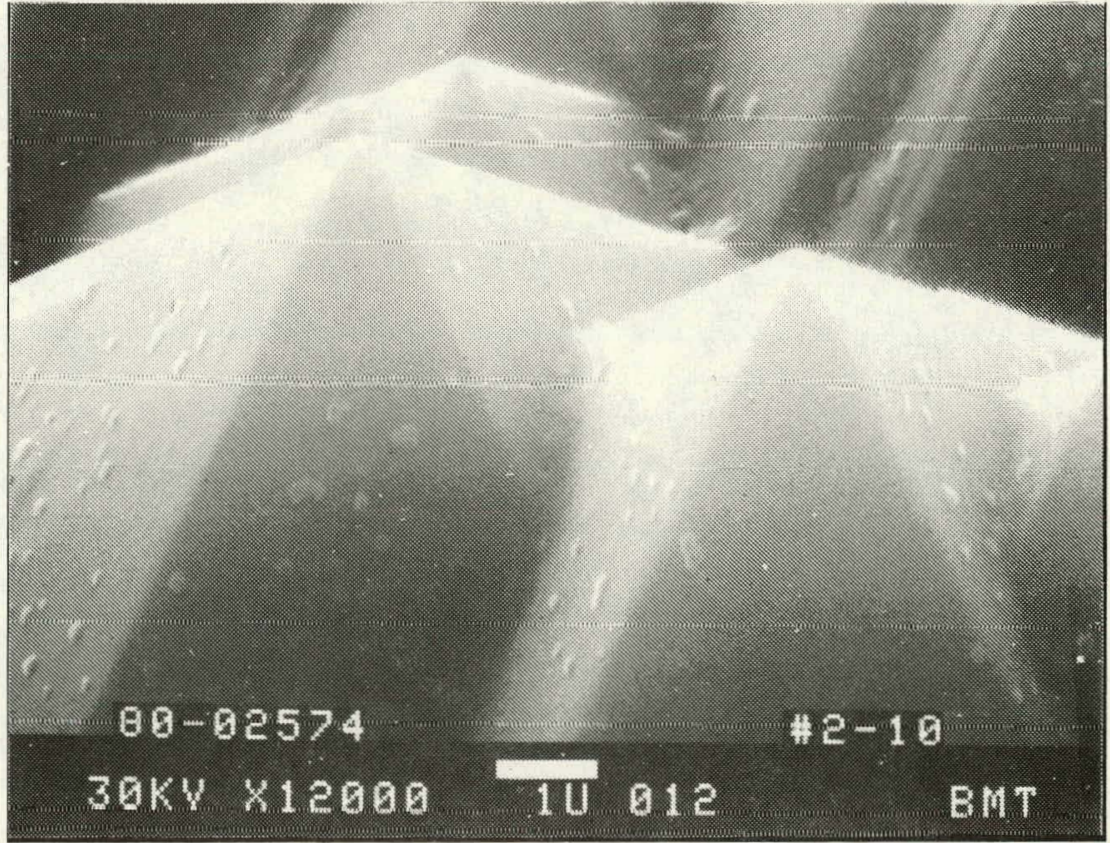

Figure 14. Textured Surface Showing Carbon Contamination 


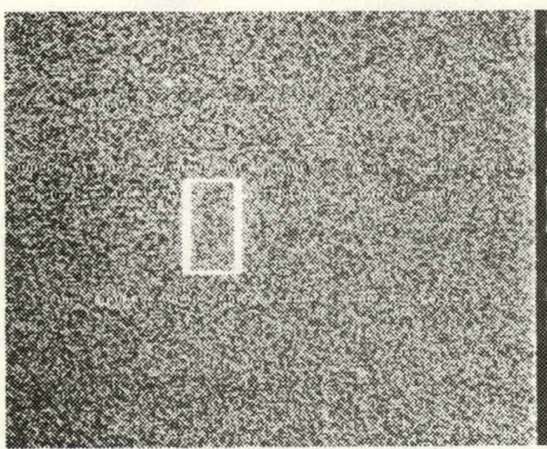

$100 x$

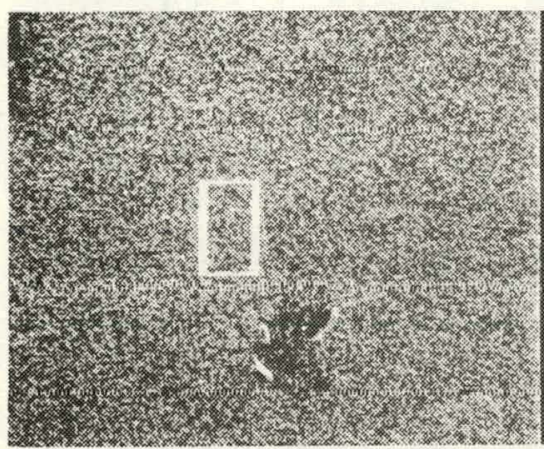

$100 x$

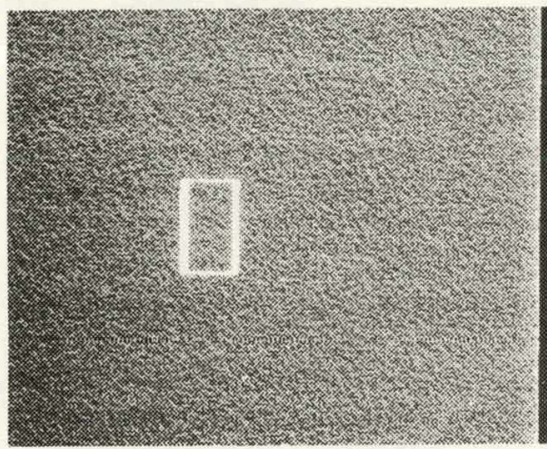

$100 x$

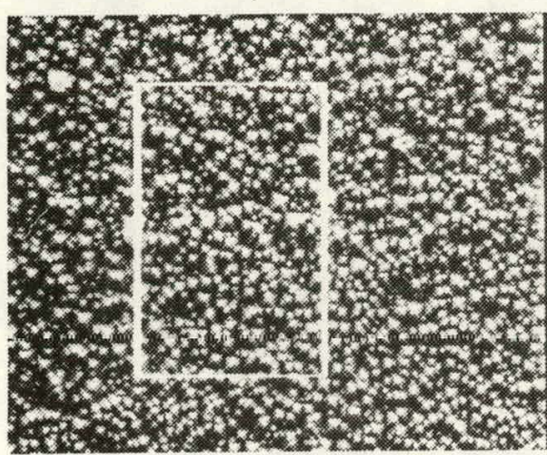

$500 \mathrm{X}$

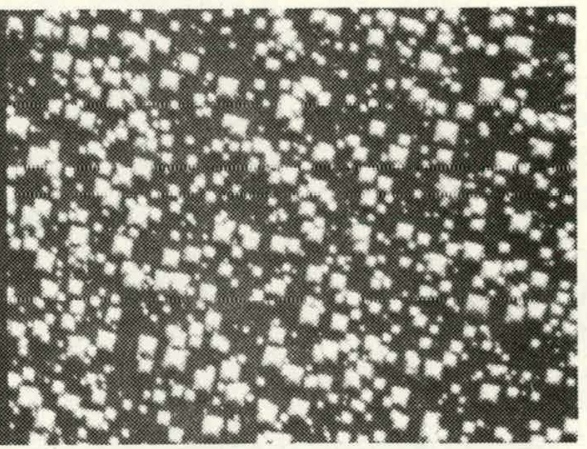

$1,000 X$
- As received

- No pattern

- 1-min etch
- As received

- No pattern

- 2-min etch
- As received

- No pattern

- 3-min etch

- As received

- No pattern

- 4-min etch

Figure 15. Effect of Texture Etch on Wafer With No Prior Processing 


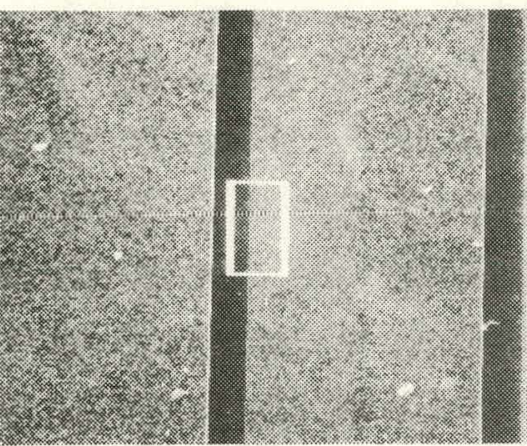

$105 \mathrm{X}$

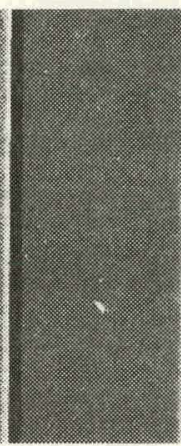

ter

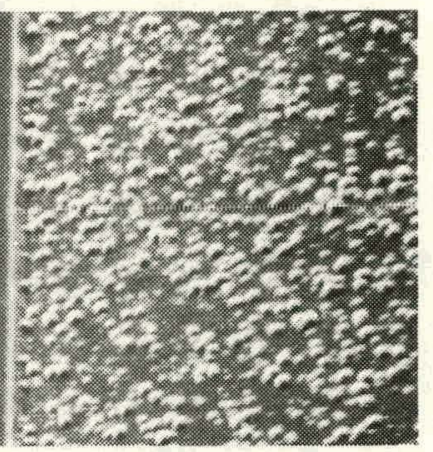

$1,050 x$ $45^{\circ} \mathrm{C}$
- Nondiffused

- With pattern

- 1-min etch

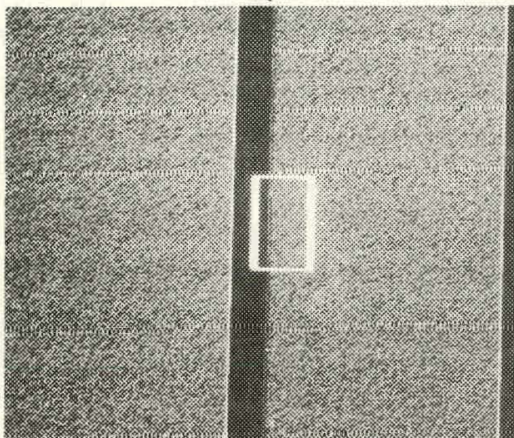

$105 X$

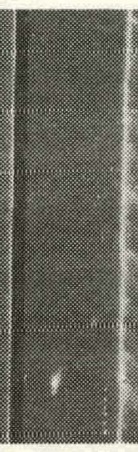

-

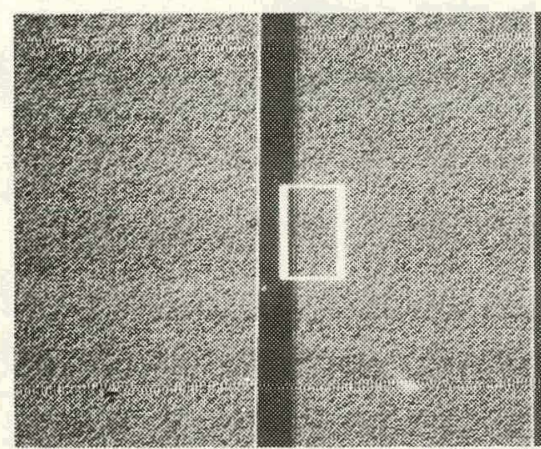

$105 X$

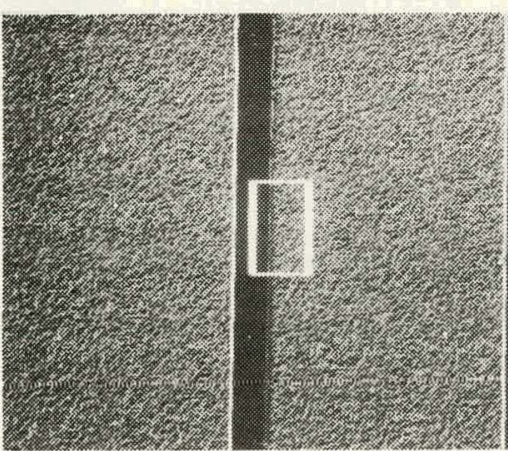

$105 X$
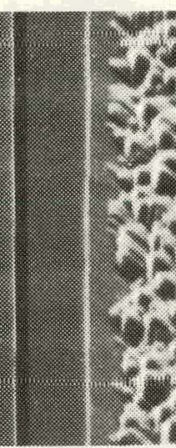

Nivil

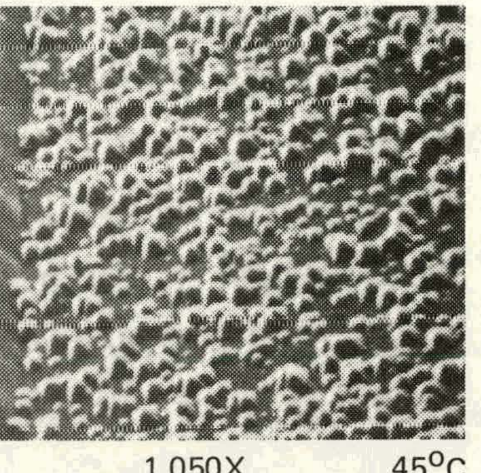

$1,050 \mathrm{X}$
- Nondiffused

- With pattern

- 2-min etch
- Nondiffused

- With pattern

- 3-min etch
- Nondiffused

- With pattern

- 4-min etch

Figure 16. Effect of Texture Etch on Wafer With Mask Processing Only 


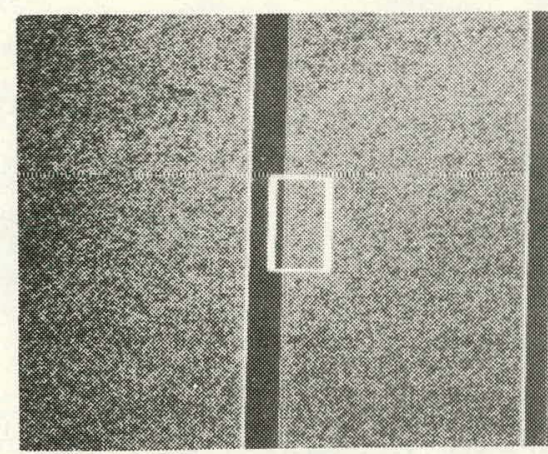

$105 \mathrm{X}$

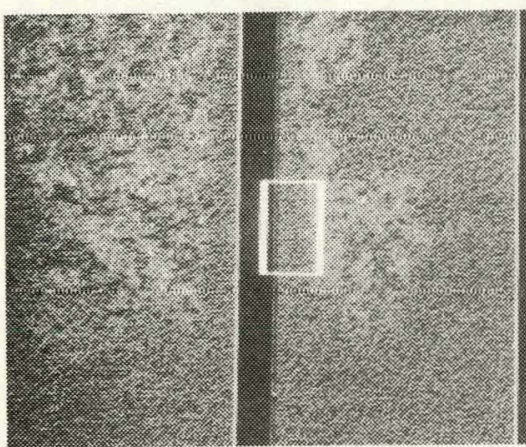

$105 x$

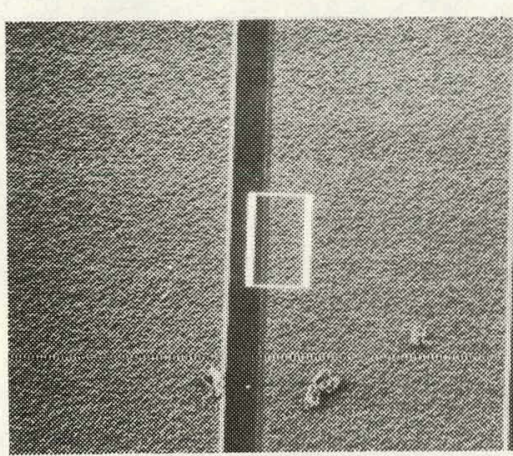

$105 x$

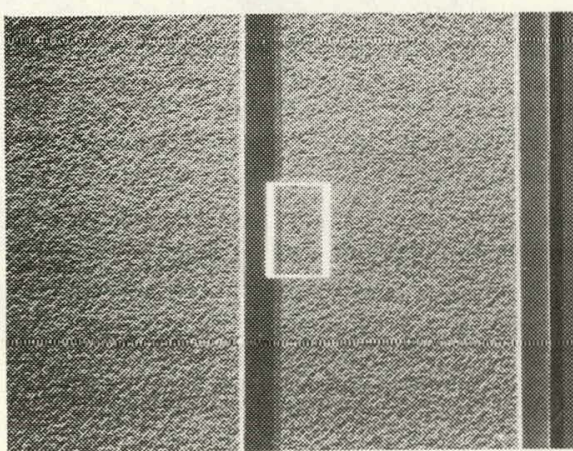

$105 x$
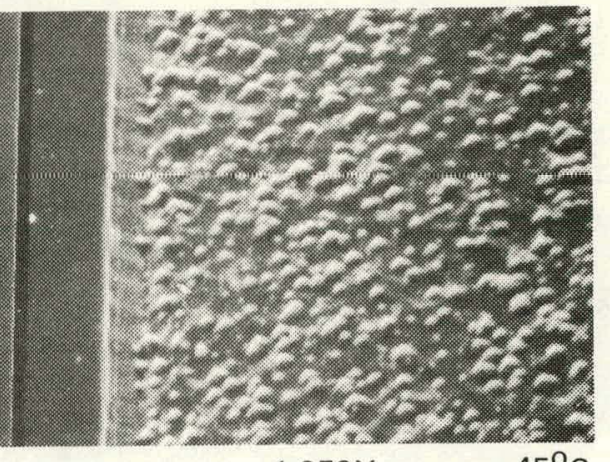

$1,050 \mathrm{X}$

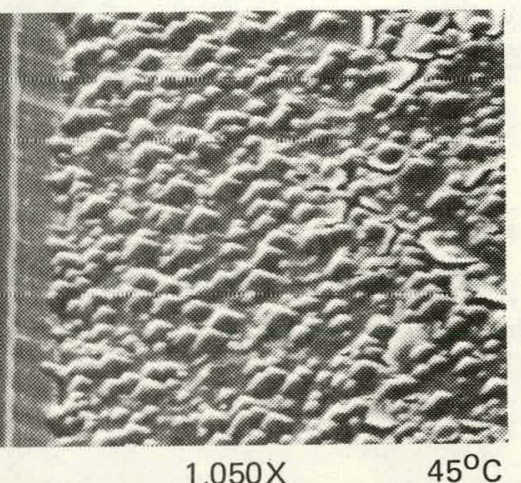

$1,050 x$
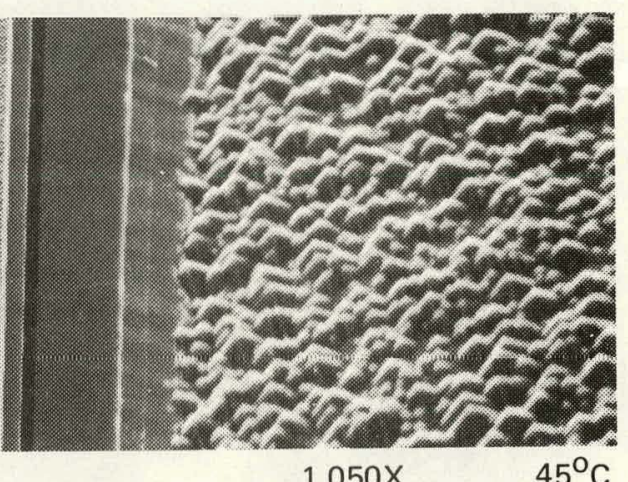

$1,050 \mathrm{X}$

$45^{\circ} \mathrm{C}$
- Diffused

- With pattern

-1-min etch
- Diffused

- With pattern

- 2-min etch
- Diffused

- With pattern

- 3-min etch
- Diffused

- With pattern

-4-min etch

Figure 17. Effect of Texture Etch on Wafer With Both Diffusion and Mask Processing 


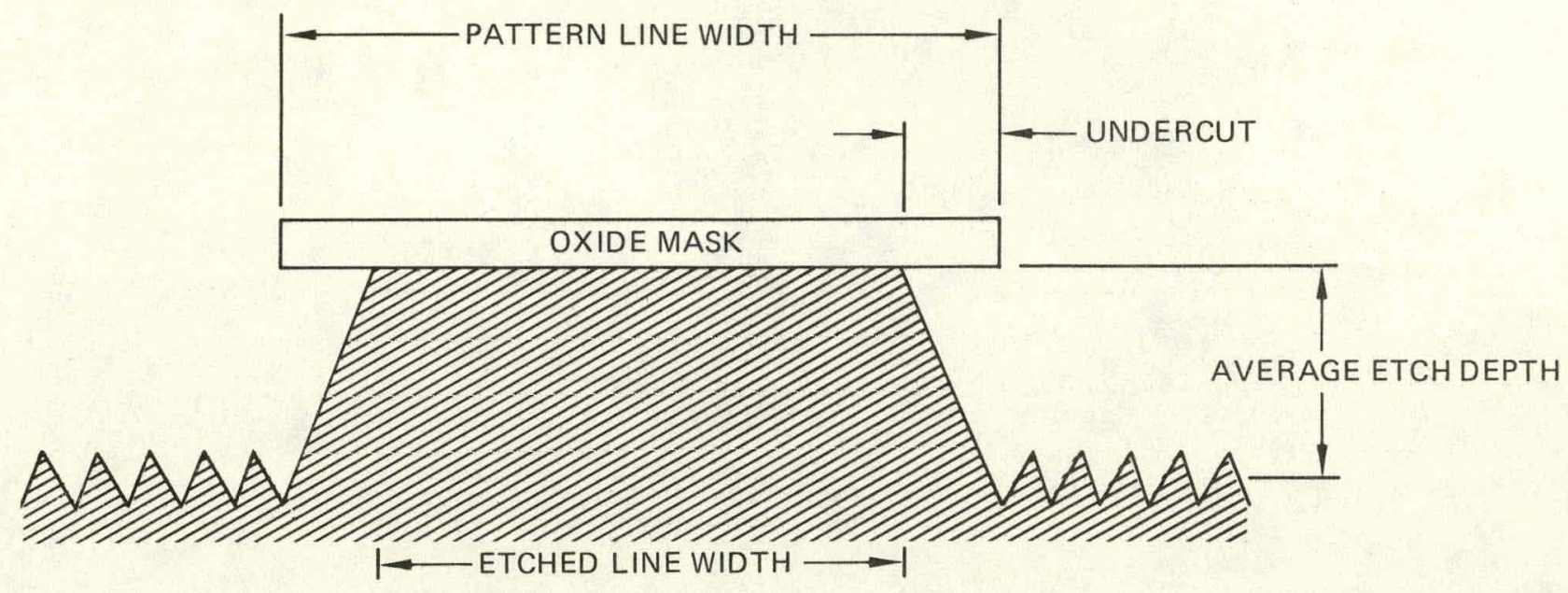

\begin{tabular}{|c|ccc|ccc|}
\hline & \multicolumn{3}{|c|}{ Nondiffused wafers } & \multicolumn{3}{c|}{ Diffused wafers } \\
\hline $\begin{array}{l}\text { Etch } \\
\text { time }(\mathrm{min})\end{array}$ & $\begin{array}{l}\text { Average etch } \\
\text { depth }(\mu \mathrm{m})\end{array}$ & $\begin{array}{l}\text { Line width } \\
(\mathrm{mil})\end{array}$ & $\begin{array}{l}\text { Undercut } \\
(\mu \mathrm{m})\end{array}$ & $\begin{array}{l}\text { Average etch } \\
\text { depth }(\mu \mathrm{m})\end{array}$ & $\begin{array}{l}\text { Line width } \\
(\mathrm{mil})\end{array}$ & $\begin{array}{l}\text { Undercut } \\
(\mu \mathrm{m})\end{array}$ \\
\hline 1 & 2.0 & 1.50 & 0 & 3.0 & 1.40 & 1.3 \\
2 & 2.5 & 1.46 & 0.5 & 4.0 & 1.40 & 1.3 \\
3 & 3.5 & 1.43 & 0.9 & 5.0 & 1.30 & 2.5 \\
4 & $4.5-5.5$ & 1.35 & 1.9 & 6.0 & 1.20 & 3.8 \\
\hline
\end{tabular}

Figure 18. Selective Texturizing Etch Test Summary 


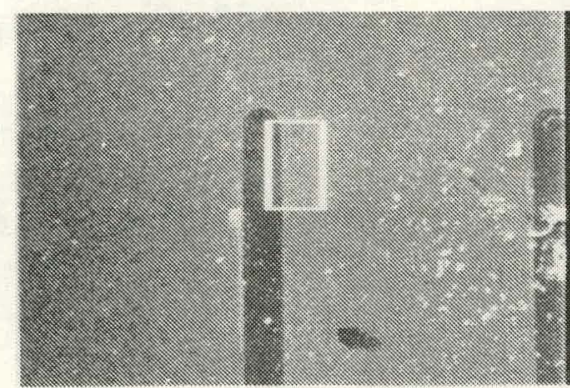

$100 x$

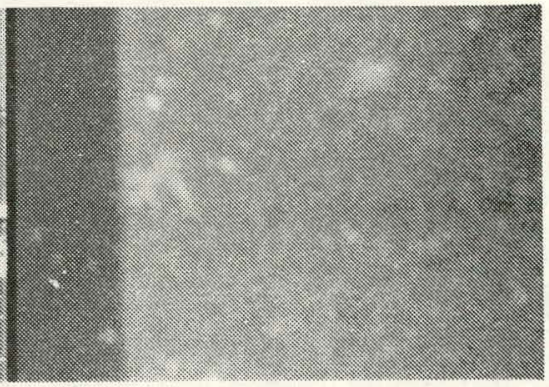

$1,000 x$

$90^{\circ} \mathrm{C}$

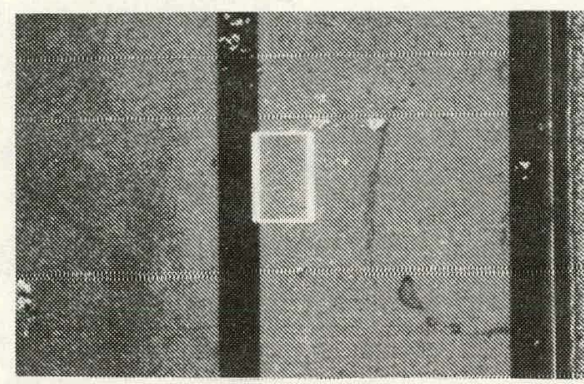

100X

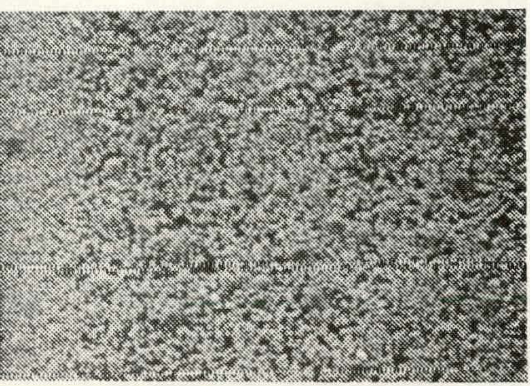

$1,000 x$ $90^{\circ} \mathrm{C}$
$2.5 \mathrm{~min}$

$5.0 \mathrm{~min}$

$7.5 \mathrm{~min}$

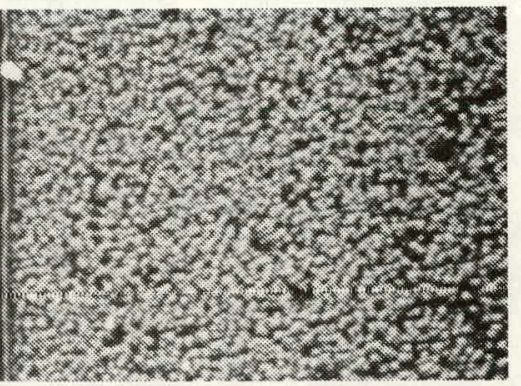

$1,000 x$

$90^{\circ} \mathrm{C}$

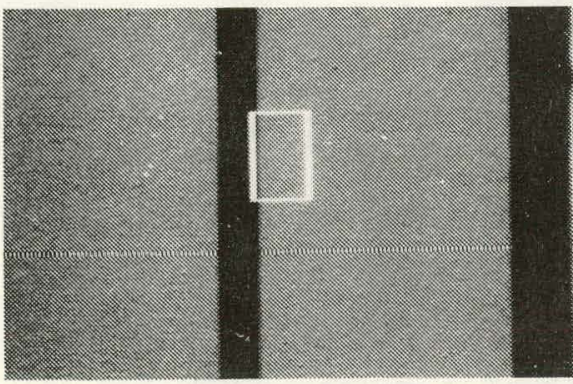

$100 x$

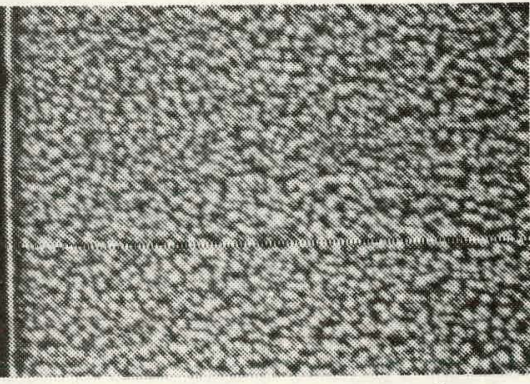

$1,000 x$

$90^{\circ} \mathrm{C}$

$10 \mathrm{~min}$

Figure 19. Selective Etched Diffused Wafor (1:1 Hydrazinc, at Room Temperature) 


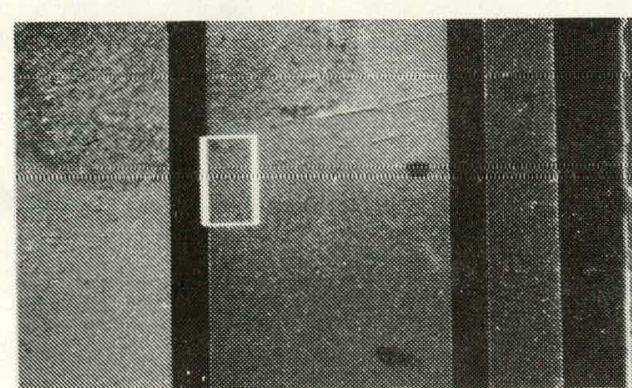

$100 x$

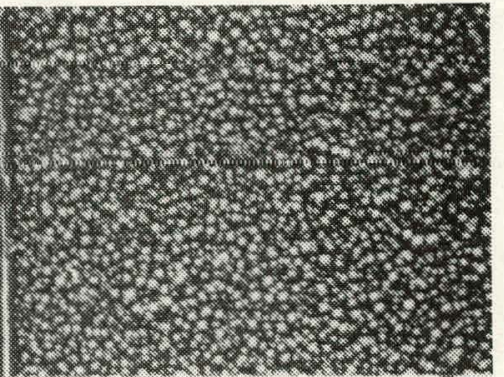

$1,000 x$

$90^{\circ} \mathrm{C}$

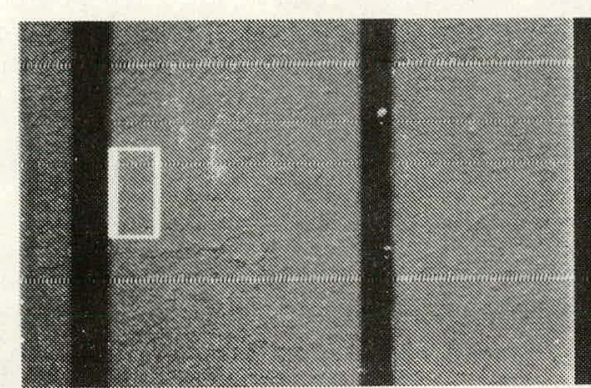

$100 \mathrm{X}$

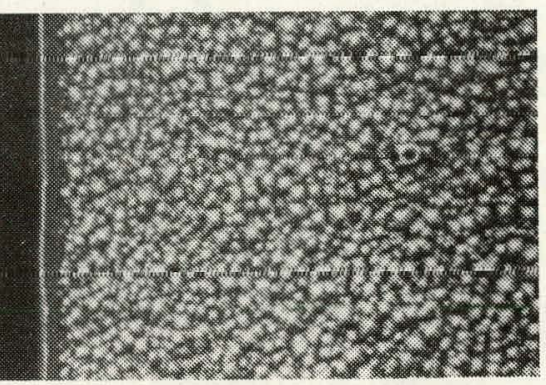

$1,000 x$

$90^{\circ} \mathrm{C}$

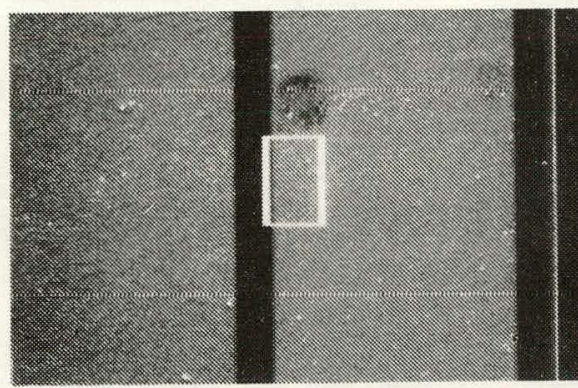

$100 x$

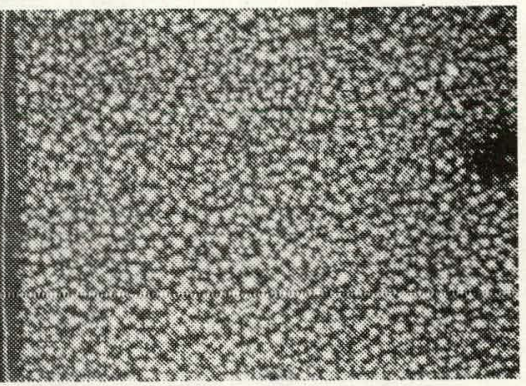

$1,000 x$

$90^{\circ} \mathrm{C}$

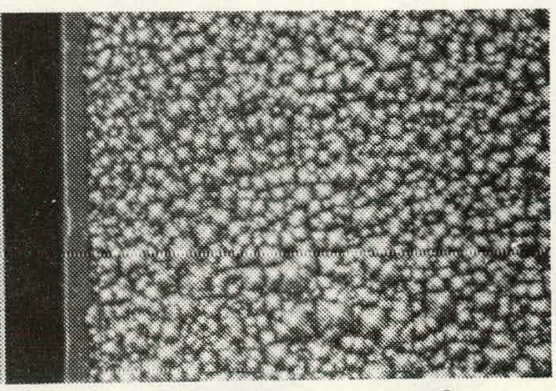

$1,000 \mathrm{X} \quad 90^{\circ} \mathrm{C}$

$30 \mathrm{~min}$

$15 \mathrm{~min}$

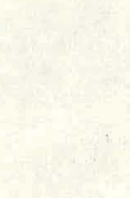

$45 \mathrm{~min}$

$60 \mathrm{~min}$

ণัণ

Figure 20. Selective Etched Diffused Wafer (1:1 Hydrazine, at Room Temperature) 


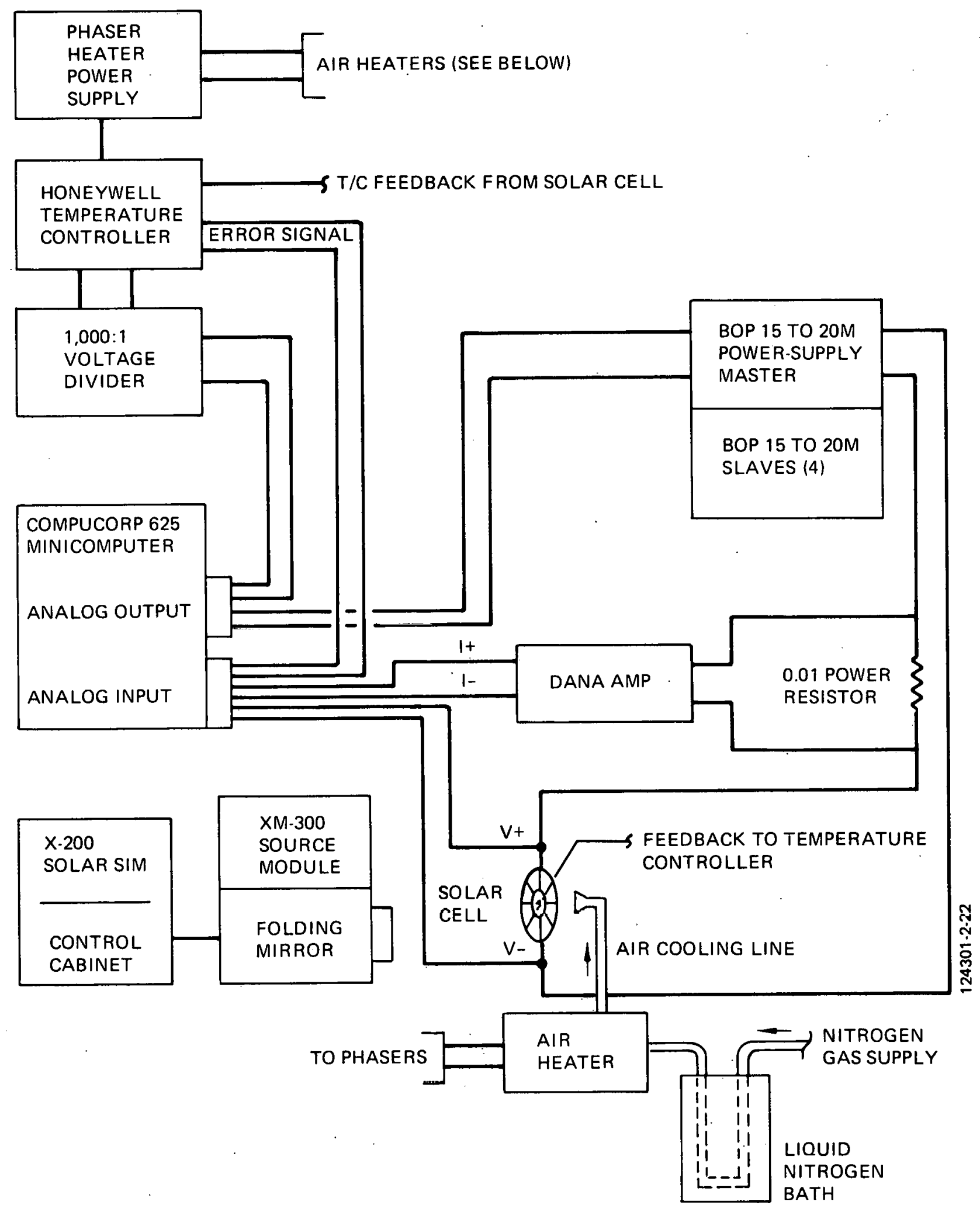

Figure 21. Schematic Representation of a Concentrator Solar-Cell Test Facility 


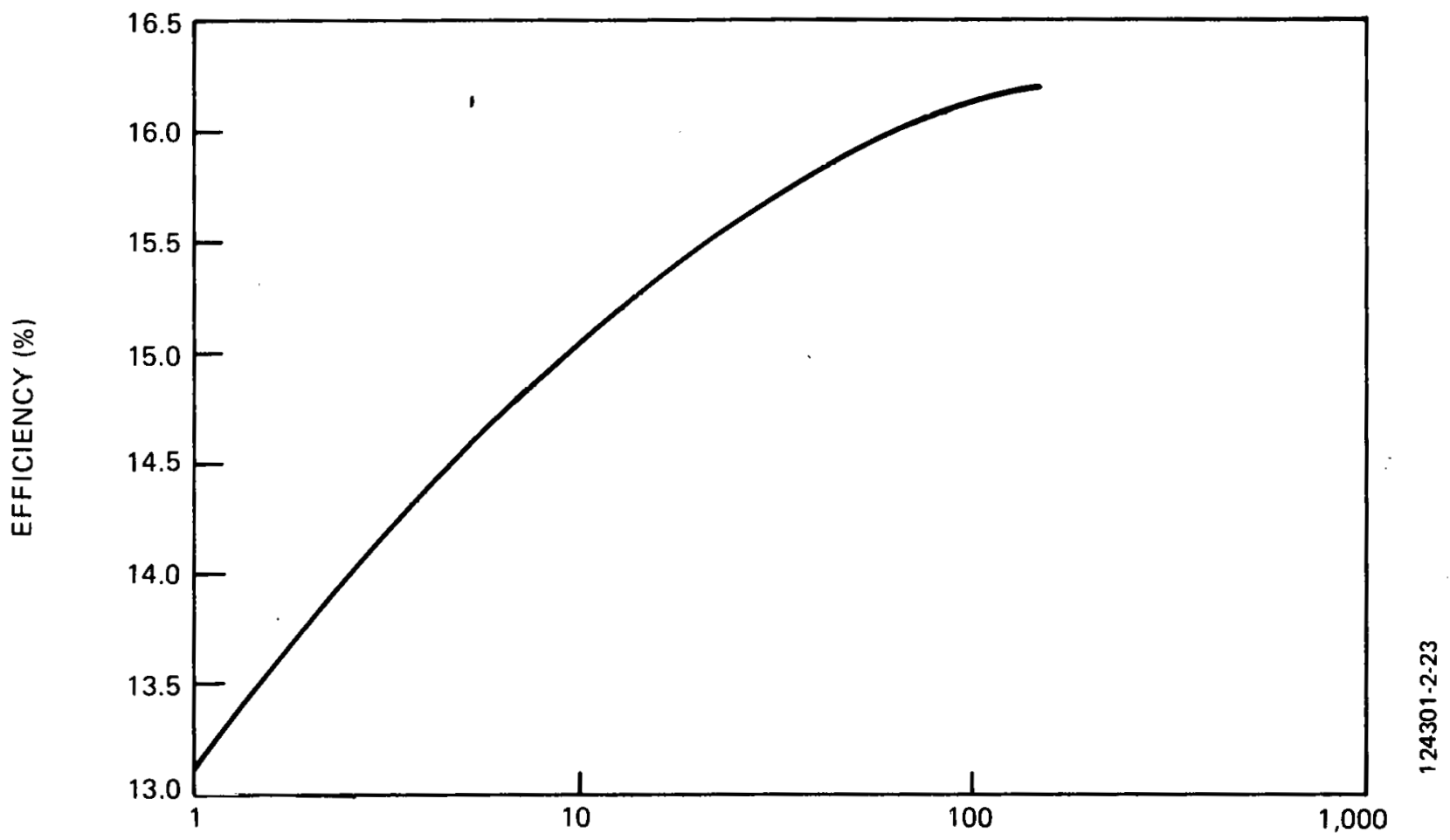

CONCENTRATION RATIO (SUNS)

Figure 22. Efficiency Versus Concentration for a Boeing Rectangular Dual Cell With Dimensions of 1.0 by 1.6 in 
Distribution :

SERI, Library (2)

1536 Cole Blvd., Bldg. \#4

Golden, CO 80401

M. B. Prince (6)

Assistant Director for Photovoltaics

Division of Solar Technology

U. S. Department of Energy

600 E Street

Washington, DC 20545

D. L. Krenz (2)

Director, Special Programs Division

Albuquerque Operations office

U. S. Department of Energy

Albuquerque, NM 87185

2144 J. L. Rodriguez (25)

2146 H. T. Weaver (25)

4700 J. H. Scott

4710 G. E. Brandvold

4720 D. G. Schueler

4724 E. C. Boes (10)

8214 M. A. Pound

3241 L. J. Erickson (5)

3151 W. L. Garner (3)

3154-3 C. H. Dalin (25)

for DOE/TIC (Unlimited Release) 